\title{
Practice Parameter for the Assessment and Treatment of Children and Adolescents With Suicidal Behavior
}

\begin{abstract}
These guidelines review what is known about the epidemiology, causes, management, and prevention of suicide and attempted suicide in young people. Detailed guidelines are provided concerning the assessment and emergency management of the children and adolescents who present with suicidal behavior. The guidelines also present suggestions on how the clinician may interface with the community. Crisis hotlines, method restriction, educational programs, and screening/ case-finding suicide prevention strategies are examined, and the clinician is advised on media counseling. Intervention in the community after a suicide, minimization of suicide contagion or imitation, and the training of primary care physicians and other gatekeepers to recognize and refer the potentially suicidal child and adolescent are discussed. J. Am. Acad. Child Adolesc. Psychiatry, 2001, 40(7 Supplement):24S-51S. Key Words: suicide, children, adolescents, suicide attempts, practice guidelines, suicide prevention, suicidal ideation, mood disorders.
\end{abstract}

Suicidal behavior is a matter of great concern for clinicians who deal with the mental health problems of children and adolescents. The incidence of suicide attempts reaches a peak during the mid-adolescent years, and mortality from suicide, which increases steadily through the teen years, is the third leading cause of death at that age. Clinicians need to know how to identify those at greatest risk for suicide from among the large number of suicide attempters who have a benign prognosis; how to provide treatment for the suicidal patient; how to advise and counsel the child, adolescent, and parental survivors of individual suicides; and how to provide expert consultation to educational and public health authorities on appropriate and inappropriate directions for suicide prevention programs. The parameter was written to aid clinicians in the assessment and treatment of children and adolescents exhibiting suicidal behavior or harboring suicidal ideation.

This parameter was developed by David Shaffer, M.D., Cynthia R. Pfeffer, M.D., and the Work Group on Quality Issues: William Bernet, M.D., Chair, Valerie Arnold, M.D., Joseph Beitchman, M.D., R. Scott Benson, M.D., Oscar Bukstein, M.D., Joan Kinlan, M.D., Jon McClellan, M.D., David Rue, M.D., and Jon Shaw, M.D. AACAP Staff: Kristin Kroeger. The authors thank David A. Brent, M.D., Markus Kruesi, M.D., Jane L. Pearson, Ph.D., and Anthony Spirito, Ph.D., for their thoughtful review, and Jennifer Gutstein for her considerable assistance. This summary and the full text of the Practice Parameter for the Assessment and Treatment of Children and Adolescents With Suicidal Behavior are available to Academy members on the World Wide Web (www.aacap.org). The full text of this parameter was reviewed at the 1999 Annual Meeting of the American Academy of Child and Adolescent Psychiatry and was approved by AACAP Council on October 17, 2000.

Reprint requests to AACAP Communications Department, 3615 Wisconsin Avenue, N. W., Washington, DC 20016.

0890-8567/01/4007-0024S@2001 by the American Academy of Child and Adolescent Psychiatry.

\section{EXECUTIVE SUMMARY}

This summary provides an overview of the assessment and treatment recommendations contained in the Practice Parameter for the Assessment and Treatment of Children and Adolescents With Suicidal Behavior. This summary includes many of the most important points and recommendations that are in these practice guidelines. However, the treatment and assessment of suicidal patients requires the consideration of many important factors that cannot be conveyed fully in a summary, and the reader is encouraged to review the entire document. Each recommendation in the executive summary is identified as falling into one of the following categories of endorsement, indicated by an abbreviation in brackets following the statement. These categories indicate the degree of importance or certainty of each recommendation.

"Minimal Standards" [MS] are recommendations that are based on substantial empirical evidence (such as well controlled, double-blind trials) or overwhelming clinical consensus. Minimal standards are expected to apply more than $95 \%$ of the time, i.e., in almost all cases. When the practitioner does not follow this standard in a particular case, the medical record should indicate the reason.

"Clinical Guidelines" [CG] are recommendations that are based on empirical evidence (such as open trials, case studies) and/or strong clinical consensus. Clinical guidelines apply approximately $75 \%$ of the time. These practices should always be considered by the clinician, but there are exceptions to their application.

"Options" [OP] are practices that are acceptable but not required. There may be insufficient empirical evidence to support recommending these practices as minimal standards or clinical guidelines. In some cases they may be the perfect thing 
to do, but in other cases they should be avoided. If possible, the practice parameters will explain the pros and cons of these options.

"Not Endorsed" [NE] refers to practices that are known to be ineffective or contraindicated.

\section{SUICIDE}

Suicide, exceedingly rare before puberty, becomes increasingly frequent through adolescence. Approximately 2,000 U.S. adolescents commit suicide each year.

The factors that predispose to completed suicide are many and include preexisting psychiatric disorders and both biological and social-psychological facilitating factors. The overwhelming proportion of adolescents who commit suicide (more than 90\%) suffered from an associated psychiatric disorder at the time of their death. More than half had suffered from a psychiatric disorder for at least 2 years.

Stress events often precede adolescents' suicides, including a loss of a romantic relationship, disciplinary troubles in school or with the law, or academic or family difficulties. These stresses may ensue from the underlying mental disorder itself (e.g., trouble with the law) or they may be normative outcomes of uncontrollable events (e.g., a death in the family) with which the adolescent with a mental disorder may not be able to cope. An adolescent with an underlying mental disorder may be faced with a greater number of stressful events than the average adolescent. Or he may perceive the events that occur as more stressful.

Suicide is much more common in adolescent and young adult males than females (the ratio grows from $3: 1$ in the rareprepubertal suicides to approximately 5.5:1 in 15-to 24-yearolds), but many of the risk factors are the same for both sexes. Mood disorders, poor parent-child communication, and a previous suicide attempt are risk factors for suicide in both boys and girls, although a previous suicide attempt is more predictive in males. Substance and/or alcohol abuse significantly increases the risk of suicide in teenagers aged 16 and older. Family pathology and a history of family suicidal behavior may also increase risk and should be investigated.

African Americans currently have a lower rate of suicide than whites, but the suicide rate of African-American adolescent and young adult males has been rising rapidly. Native American and Alaskan Native youth have historically had a very high rate of suicide. Attempted suicide rates of Hispanic youth are greater than those of white and African-American youth. Clinicians should consider the cultural background of a suicidal youth and assess cultural attitudes in the child's community. However, ethnic differences in the suicide rate may reflect contagion in isolated groups rather than cultural differences.

\section{SUICIDAL IDEATION}

Suicidal thoughts are common in children and adolescents of both genders and are by no means always associated with other features of psychopathology. They usually come to clinical attention when enunciated as threats.

Disruptive disorders increase the risk of suicidal ideation in children 12 years old and younger, and substance use or separation anxiety may provoke adolescent ideators of both sexes to attempt suicide. Mood and anxiety disorders increase the risk of suicidal ideation. Panic attacks are a risk factor for ideation or attempt in females, while aggressiveness increases the risk of suicidal ideation or attempt in males. Adolescent suicide attempters may differ from ideators in having more severe or enduring hopelessness, isolation, suicidal ideation, and reluctance to discuss suicidal thoughts.

\section{ATTEMPTED SUICIDE}

Mood disorders (particularly early-onset major depressive disorder), anxiety disorders, substance abuse, and runaway behavior independently increase the risk of suicide attempts in both sexes. Suicide attempts are more common in girls than boys (approximately 1.6:1).

Suicide attempts are considerably less common than suicidal ideas, but they are the presenting complaint in a sizable proportion of adolescents referred to mental health professionals. It is estimated that each year, approximately 2 million U.S. adolescents attempt suicide, and almost 700,000 receive medical attention for their attempt.

Teen suicide attempters are much more likely than those who only ideate to have associated psychopathology, especially a mood disorder, but the attempts often occur in the context of a relatively brief adjustment reaction.

Having made a previous suicide attempt greatly increases the risk of a boy's eventually committing suicide, but the predictive effect in females is less substantial. Only half of all suicide completers have made a known suicide attempt before their death; however, our information on previous attempts remains incomplete, as many attempts go unreported. Gay, lesbian, and bisexual youth are at increased risk for suicide attempts, often having multiple risk factors (i.e., depression, prior suicide attempts, substance abuse, sexual victimization, family conflict, and ostracism at school), as are adolescents who have been victims of childhood sexual or physical abuse.

Even the most skilled clinician can find it difficult to differentiate between benign and ominous suicidal behavior. Many adolescents who have made a medically serious attempt will never do so again, while others who have made what seemed like only a mild "gesture" may eventually commit suicide. The term "gesture," used by some clinicians to denote a nonlethal, self-destructive action that is deemed a cry for help or a manipulation without serious intent, is therefore misleading, because it minimizes the potential risk for future suicidal behavior. One cannot gauge future suicidal behavior. However, research has provided some broad indicators about risk factors and the assessment of attempters (Tables 1 and 2) that need to be considered by all clinicians [MS]. 
TABLE 1

High-Risk Factors for Suicide in Adolescents

Males at much higher risk than females

Among males

Previous suicide attempts

Age 16 or older

Associated mood disorder

Associated substance abuse

Among females

Mood disorders

Previous suicide attempts

Immediate risk predicted by agitation and major depressive disorder

\section{ASSESSMENT}

Assessment of suicidal patients requires an evaluation of the suicidal behavior and determination of risk for death or repetition, as well as an assessment of the underlying diagnoses or promoting factors.

\section{Identification of Risk}

Clinicians should be aware of which adolescent suicide attempters are at greatest risk for later suicide (Table 2) [MS]. These are older (16- to 19-year-old) male adolescents or adolescents of either gender, regardless of age, with a current mental disorder or disordered mental state, such as depression, mania or hypomania, or mixed states, especially when complicated by comorbid substance abuse, irritability, agitation, or psychosis. Attempters who have made prior suicide attempts, those who used a method other than ingestion or superficial cutting, and those who still want to die are also at higher risk.

Clinicians should ascertain the suicidality of depressed adolescents (i.e., whether and how often they think about suicide and whether they have ever attempted suicide). If suicidal ideation or recent suicidal behavior is present in a depressed teenager, he or she should continue to be monitored [MS].

Assessment information should always be drawn from several sources, including child or adolescent, parents or guardians, school reports, and any other individuals close to the child. Structured or semistructured suicide scale questionnaires, whether delivered by the clinician or self-completed by the child or adolescent, have limited predictive value. They may complement but should never take the place of a thorough assessment or substitute for any aspect of assessment.

\section{TREATMENT}

Treatment must encompass the acute management of suicidal behavior as well as treatment of associated mental disorders.

\section{Acute Management}

Emergency room and other crisis staff should establish a relationship with the suicidal individual and family and establish the importance of treatment [MS].
TABLE 2

Checklist for Assessing Child or Adolescent Suicide Attempters in an Emergency Room or Crisis Center

\begin{tabular}{l} 
Attempters at Greatest Risk for Suicide \\
\hline Suicidal history \\
Still thinking of suicide \\
Have made a prior suicide attempt \\
Demographics \\
Male \\
Live alone \\
Mental state \\
Depressed, manic, hypomanic, severely anxious, or have a \\
mixture of these states \\
Substance abuse alone or in association with a mood disorder \\
Irritable, agitated, threatening violence to others, delusional, or \\
hallucinating
\end{tabular}

Do not discharge such patients without psychiatric evaluation.

Look for signs of clinical depression

Depressed mood most of the time

Loss of interest or pleasure in usual activities

Weight loss or gain

Can't sleep or sleeps too much

Restless or slowed-down

Fatigue, loss of energy

Feels worthless or guilty

Low self-esteem, disappointed with self

Feels hopeless about future

Can't concentrate, indecisive

Recurring thoughts of death

Irritable, upset by little things

Look for signs of mania or hypomania

Depressed mood most of the time

Elated, expansive, or irritable mood

Inflated self-esteem, grandiosity

Decreased need for sleep

More talkative than usual, pressured speech

Racing thoughts

Abrupt topic changes when talking

Distractible

Excessive participation in multiple activities Agitated or restless

Dypersexual, spends foolishly, uninhibited remarks

Source: American Foundation for Suicide Prevention (1999), Today's suicide attempter could be tomorrow's suicide (poster). New York: American Foundation for Suicide Prevention, 1-888-333-AFSP.

Although there have been no randomized controlled trials to determine whether hospitalizing high-risk suicide attempters saves lives, clinicians should be prepared to admit suicide attempters who express a persistent wish to die or who have a clearly abnormal mental state [MS]. Inpatient treatment should continue until their mental state or level of suicidality has stabilized [MS].

Regardless of the apparent mildness of the patient's suicidal behavior, the clinician must obtain information from a third party. Discharge can be considered if the clinician is satisfied 
that adequate supervision and support will be available over the next few days and if a responsible adult has agreed to "sanitize" the environment by securing or disposing of potentially lethal medications and firearms [MS].

The most common method used by adolescents to commit suicide in the United States is with a firearm. Ingestion of medication is the most common method adolescents use to attempt suicide. Availability and presence in the home of firearms and lethal medication must be determined during assessment, and parents must be explicitly told to remove firearms and lethal medication [MS]. It is valuable for the clinician to warn the adolescent (and the parents) about the dangerous disinhibiting effects of alcohol and other drugs [CG].

The value of "no-suicide contracts," in which the child or adolescent agrees not to engage in self-harming behavior and to tell an adult if he or she is having suicidal urges, is not known. The child or adolescent might not be in a mental state to accept or understand the contract, and both family and clinician should know not to relax their vigilance just because a contract has been signed.

If possible, an appointment should be scheduled for the child or adolescent to be seen for a fuller evaluation before discharge from the emergency room. If this is not possible, a telephone contact for a parent or other caretaker should be obtained and a procedure set up for clinical staff, if they have not been contacted by the parent within a reasonable period of time, to themselves initiate the contact [MS].

The clinician treating the suicidal child or adolescent during the days following an attempt should be available to the patient and family (for example, receive and make phone calls outside of therapeutic hours) or have adequate physician coverage if away [MS], have experience managing suicidal crises [MS], and have support available for himself or herself [CG].

Once a therapeutic alliance is established and the adolescent attends the first treatment sessions, he or she is more likely to continue treatment.

\section{Psychotherapies}

Psychotherapy, an important component of treatment for the mental disorders associated with suicidal behavior, should be tailored to a child's or adolescent's particular need [MS]. Cognitivebehavioral therapy (CBT), interpersonal psychotherapy for adolescents (IPT-A), dialectical-behavioral therapy (DBT), psychodynamic therapy, and family therapy are all options [OP].

\section{Psychopharmacology}

As with psychotherapies, psychopharmacology to treat suicidal behavior should be tailored to a child's or adolescent's placement-specific needs. Lithium greatly reduces the rate of both suicides and suicide attempts in adults with bipolar disorder. Discontinuing lithium treatment in bipolar patients is associated with an increase in suicide morbidity and mortality.
Selective serotonin reuptake inhibitors (SSRIs) reduce suicidal ideation and suicide attempts in nondepressed adults with cluster B personality disorders. They are safe in children and adolescents, have low lethality, and are effective in treating depression in nonsuicidal children and adolescents. There have been some reports that SSRIs may have a disinhibiting effect (especially in patients with SSRI-induced akathisia) and increase suicidal ideation in a small number of adults not previously suicidal. Further controlled research is necessary to determine whether there is an association in children and adolescents. However, it would be prudent to carefully monitor children and adolescents on SSRIs to ensure that new suicidal ideation or akathisia are noted [MS].

Tricyclic antidepressants should not be prescribed for the suicidal child or adolescent as a first line of treatment [NE]. They are potentially lethal, because of the small difference between therapeutic and toxic levels of the drug, and have not been proven effective in children or adolescents.

Other medications that may increase disinhibition or impulsivity, such as the benzodiazepines and phenobarbital, should be prescribed with caution [OP]. Any and all medications prescribed to the suicidal child or adolescent must be carefully monitored by a third party, and any change of behavior or side effects must be reported immediately [MS].

\section{PREVENTION}

Public health approaches to suicide prevention have targeted suicidal children or adolescents, the adults who interact with them, their friends, pediatricians, and the media.

Teenagers may be made aware of the existence of crisis hotlines [OP]. Although widely used, early studies, hampered by methodological deficiencies, failed to show that hotlines reduce the incidence of suicide. But it would be wise to assume that their value remains untested. Research has uncovered some hotline deficiencies, but new studies are needed to determine whether correcting these problems can increase their effectiveness.

Public health measures, such as restricting young people's access to firearms, may result in a short-term reduction in the rates of suicide, but there is not yet evidence that this effect would be lasting $[\mathrm{OP}]$. Raising the minimum legal drinking age for young adults appears to reduce the suicide rate in the affected age group.

Suicide awareness programs in schools frequently minimize the role of mental illness and, although designed to encourage self-disclosure by students or third-party disclosure by their friends, have not been shown to be effective either in reducing suicidal behavior or increasing help-seeking behavior.

Because curriculum-based suicide awareness programs disturb some high-risk students, a safer approach might be to focus on the clinical characteristics of depression or other mental illnesses that predispose to suicidality. In the absence of evidence to the 
contrary, talks and lectures about suicide to groups of children and adolescents drawn from regular classes should be discouraged [NE]. This is because of their propensity to activate suicidal ideation in disturbed adolescents whose identity is not usually known to the instructor. Screening or suicide education programs for teenagers that do not include procedures to evaluate and refer identified ideators or attempters are not endorsed [NE]. Direct screening programs may identify those with underlying risk factors to a clinician for further evaluation [OP].

Primary practitioners, counselors, or others who may lack the time, resources, or training to evaluate a child's or teenager's mental state should make use of self-completion questionnaires to screen for depression, suicidal preoccupations, and previous suicidal behavior in their office [CG]. There is ample evidence that teenagers in mid to late adolescence- the group that is at greatest risk for suicide attempt and completionwill, if asked directly, reveal this information. This practice can be especially recommended to family practitioners, pediatricians, school counselors, juvenile justice professionals, and psychologists who wish to survey their populations for teenagers at high risk for suicide. Those identified as being at risk should be referred for further evaluation and treatment, if necessary, and receive support and follow-up (i.e., phone calls, case manager if available) during the transition period.

Clinicians engaged in public health practice should be able to advise media reporters and editors on the dangers of excessive coverage of individual suicides [OP].

Finally, primary care physicians and gatekeepers should be trained to recognize risk factors for suicide and suicidal behavior and, when necessary, refer to a mental health clinician [CG].

\section{POSTVENTION}

After a suicide, the relative, friends, and teachers of the child or adolescent who committed suicide may benefit from intervention to facilitate grieving, reduce guilt and depression, and decrease the effects of guilt and trauma. There may also be a call to intervene to minimize the risk of imitative or copycat suicides, but there is no agreement about how this should be done [CG].

\section{LITERATURE REVIEW}

The literature on child and adolescent suicidal behavior has burgeoned since the early 1980s. Journal articles and books published from 1980 through February 2000 were reviewed via a National Library of Medicine search of the topics "suicide" and "suicidal behavior" in children and adolescents. There were more than 20,000 publications listed in PSYCInfo, Healthstar, and Medline during this period. Only the most relevant articles are cited due to space constraints. Key references are marked with an asterisk. The authors also drew from their clinical knowledge and experience, writing, and research in this subject area.

\section{HISTORICAL REVIEW}

Until the late 1950s, the literature on suicide was confined to case reviews, reviews of the demography of suicide drawn from death certificate data, and speculation about the dynamics of the behavior. The late 1950s saw the first systematic psychological autopsy study that was carried out by Eli Robins and his colleagues (1959) at Washington University, St. Louis, followed by similar studies using the same techniques in other countries. These studies formed a milestone because they gave evidence for the importance of psychiatric disorder as the proximal cause of most suicides.

The 1960s saw the start of a period of increasing young male suicides that was to continue for three decades (National Center for Health Statistics, 1999). Although the period was marked by a growth in the suicide prevention movement in the United States, with its emphasis on crisis intervention services, relatively little informative research emerged.

By the early 1980s, the suicide rate in white, male teenagers had more than doubled (National Center for Health Statistics, 1999), and this attracted public attention. The occurrence of several clusters of suicides among children and adolescents alarmed the general public and stimulated efforts to develop methods of understanding and preventing youth suicide. A task force of clinical and research experts was convened by the U.S.

Department of Health and Human Services of the Public Health Service to develop policies to reduce rates of youth suicide, and its report was published in 1989 (Alcohol, Drug Abuse, and Mental Health Administration, 1989). By that time, systematic research was being undertaken in several different centers, and much of the research on suicide in the 1980s and 1990s focused on suicide in individuals younger than the age of 19. Epidemiological and phenomenological studies flourished; efforts at suicide prevention among high school students proliferated, while at the same time substance abuse rates_almost certainly an important contributor to suicide in this age groupdeclined.

It is clear that we have a good deal of substantive information on the characteristics of suicide victims, less about child and adolescent attempters, and little systematic evidence-based knowledge about the optimal treatment of the suicidal child or adolescent. There have been very few randomized controlled trials designed to assess different forms of treatment. As a result, many of the suggestions for clinical management that are laid out in these guidelines are based on the experience and observations of clinicians who have treated this common condition. The clinician should be clear that this is a situation in which there is an absence of research and not one in which adequate research has produced ambiguous or negative findings. It is the impression of many clinicians that the majority of suicide attempters and their families benefit from straightforward interventions dictated by the child's or adolescent's mental state and family circumstances. 


\section{SUICIDE}

\section{EPIDEMIOLOGY}

Age

In 1997, the age-specific mortality rate from suicide for 10 - to 14-year-olds was 1.6 per 100,000 (National Center for Health Statistics, 2000). Although 10- to 14-year-olds represented $7 \%$ of the U.S. population, the 330 child suicides that occurred among them represented only $1 \%$ of all suicides, with most deaths in this group occurring in youth aged 12 to 14 years.

In 1997, the suicide mortality rate for 15- to 19-year-olds was 9.5 per 100,000 (National Center for Health Statistics, 2000). That is approximately six times as high as in the younger age group. The suicide rate among boys was 15.2 per 100,000 and among girls, 3.4 per 100,000 . The proportion of suicides that occur in this age group (6.6\% of the general population) approaches the proportion of this age group in the general population $(6 \%)$.

In 1997, the suicide mortality rate for 20- to 24-year-olds was 13.6 per 100,000 (National Center for Health Statistics, $2000)$. This age group represents $7 \%$ of the total population but accounts for $8 \%$ of all suicides.

Suicide rates (1997) in childhood and adolescence, grouped by different gender and ethnic groups, are shown in Figure 1.
Overall, approximately 2,000 U.S. adolescents (aged 13-19 years) commit suicide each year (National Center for Health Statistics, 2000).

\section{Gender}

In the United States the ratio of male to female suicide in young children is approximately 3:1, but thereafter the rate increases rapidly for boys and only slightly for girls, so that among 15- to 19-year-olds it is 4.5:1 and among 20- to 24year-olds it is greater than 6:1 (National Center for Health Statistics, 2000).

\section{Secular Changes}

During the three decades between the early 1960s and the late 1980s, the suicide rate among 15- to 19-year-old males increased 3-fold. The increase was not universal, and there was little change in the female rate. While the rate among 10- to 14year-olds (National Center for Health Statistics, 1999) has doubled since 1979 , the rate is very low, so large proportionate increases can result from a very small increase in cases (see Fig. 2 for details).

Teen suicide rates have increased for whites and AfricanAmerican males since the early 1960s (National Center for Health Statistics, 1999). The rate among whites reached a peak in

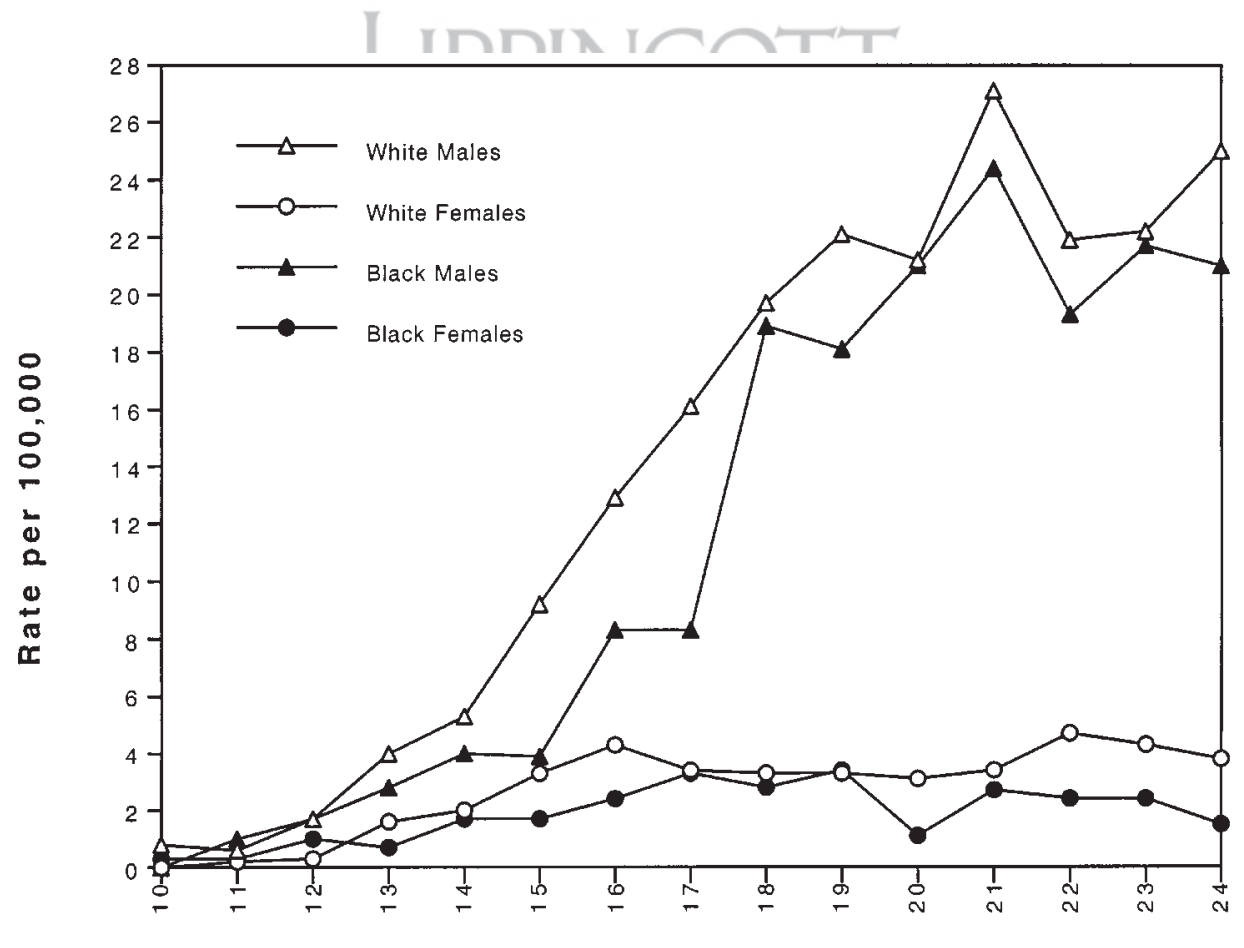

Age

Fig. 1 Suicide rates per 100,000 population (ages 10-24), 1997. Source: National Center for Health Statistics (1999). 


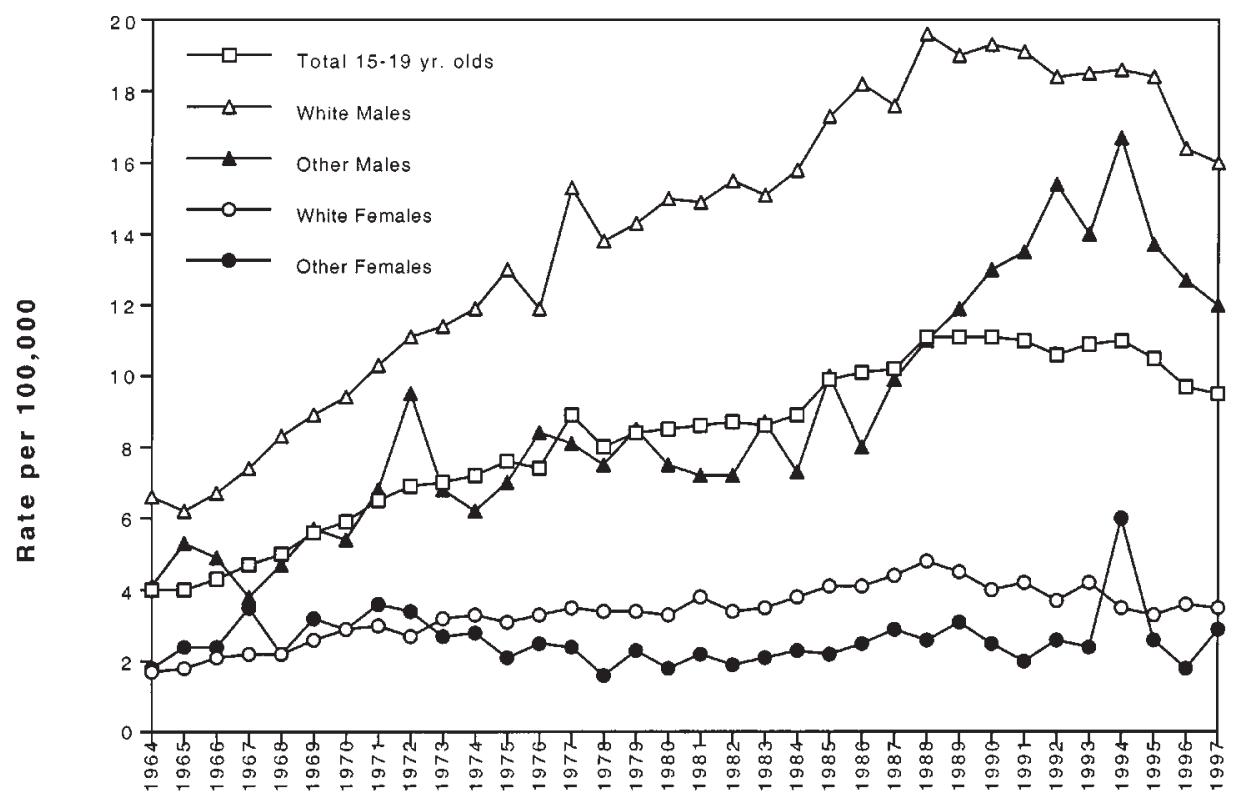

Year

Fig. 2 Adolescent suicide rates per 100,000 population (ages 15-19), 1964-1997. The "other" groups include all nonwhites. Sources: National Center for Health Statistics (1999); National Center for Health Statistics (2000).

1987 and has since declined. The African-American male suicide rate increased dramatically after 1986, but since 1994 it too has declined. The fluctuations in the suicide rate appear to be real, rather than due to any methodological artifact (e.g., due to changes in reporting practices), because the rate of undetermined (whether suicidal or accidental) deaths changed in parallel.

Suggested reasons for the increase in suicidal behavior among teenage boys are increased availability of firearms (Boyd and Moscicki, 1986; Brent et al., 1991) and increased substance use in the youth population (Brent et al., 1987). Brent found that firearms were twice as likely to be found in the homes of adolescent suicide victims as in the homes of attempters or psychiatric controls (Brent et al., 1991), and Brent and Kellermann found that firearms were significantly more likely to be found in the homes of those who completed suicide than in the homes of neighborhood controls (Brent et al., 1993c; Kellermann et al., 1992). However, it is not known whether, in certain communities, firearm ownership is independently associated with other risk factors for suicide, and the findings from Brent and colleagues' studies in the Pittsburgh area have not been replicated with adolescents elsewhere or in other countries.

Loaded guns were particularly potent risk factors for the small number of suicides without diagnosed psychopathology (Brent et al., 1993b; Kellermann et al., 1992). Laws restricting access to firearms are associated with a significant reduction in unintentional firearm deaths in youth under 15 , but the change in homicides and suicides is inconsistent (Cummings et al., 1997; Loftin et al., 1991).
Although the rate of suicide by firearm increased more than the rate of suicide by other methods (Boyd and Moscicki, 1986; Brent et al,, 1987), suicide rates increased markedly in many other countries in Europe, in Australia, and in New Zealand, where suicide by firearms is rare. In New Zealand, for example, there has been an alarming increase in hanging. Therefore, there may be some other factor at play in the worldwide increase in young male suicides. Although it is possible, it seems implausible that different mechanisms should be coincidentally operating to promote the almost universally observed phenomenon of increased risk of male youth suicide.

The reasons offered for the recent decline in suicide rates include lowered substance and alcohol use rates among the young (Centers for Disease Control and Prevention, 1998) and greatly increased prescribing of antidepressants to depressed individuals, with the largest increase in child, adolescent, and young adult populations (Olfson et al., 1998).

\section{Geography}

Suicide rates in the United States are highest in the western states and Alaska and lowest in the southern, north central, and northeastern states. The ratio of white to African-American rates is greatest in the South (Shaffer et al., 1994). Although regional discrepancies between African Americans and whites are diminishing, the lowest rates for both African-American and white suicides remain in the Deep South and the Northeast (Shaffer et al., 1994). 


\section{Methods}

Firearms are the most common method by which Americans of all ages, ethnicities, and genders commit suicide. However, there are some significant differences between genders in the use of other methods. From 1980 to 1995, firearm suicides increased among young males, with the greatest proportional increase being among African-American teenage males (300\% increase). The white teen suicide by firearm increase was $29 \%$ (National Center for Health Statistics, 1999).

While Brent et al. (1987) found that autopsies of teenagers who committed suicide by firearm were five times as likely to reveal detectable blood alcohol levels as those of teenagers who used other suicide methods, this finding was not replicated in the New York Teen Suicide Study (Fisher et al., 1995). In the same vein, specific links between method choice and type of psychopathology (e.g., alcohol abuse) have not been shown.

The methods used to commit suicide show great geographic variation. This may reflect availability. For example, in the northeastern United States, an area with strong firearm-control laws, firearms are used more often in rural areas, where, presumably, more firearms are available for sporting purposes; jumping from a height is more prevalent in urban areas, with their tall buildings; and asphyxiation by carbon monoxide exhaust is most common in suburban areas, where adolescents have access to cars and garages.

Ingestions account for approximately $16 \%$ of 15 - to 24 -yearold female suicides, but for only $2 \%$ of suicides in males that age (National Center for Health Statistics, 2000).

\section{CLINICAL CHARACTERISTICS OF TEENAGERS WHO COMMIT SUICIDE}

Completed suicide occurs most commonly in older adolescents, but it can also occur in children as young as 6 years old (Fig. 1). Psychological autopsy studies (Brent et al., 1999; Marttunen et al., 1991; Shaffer et al., 1996a) show that approximately $90 \%$ of adolescent suicides occur in individuals with a preexisting psychiatric disorder. In approximately half of these, the psychiatric disorder has been present for 2 or more years. The most common forms of psychiatric disorder found in completed suicides are (1) some form of mood disorder, which in boys is often comorbid with conduct disorder or substance abuse, and (2) substance and/or alcohol abuse, particularly in boys older than age 15 . Comorbidity between different disorders is common. Many children and adolescents who committed suicide were notably irritable, impulsive, volatile, and prone to outbursts of aggression. However, this pattern of behavior is by no means universal. Anxious children without comorbidity may have shown no overt signs of disturbance, were often excellent students, and were well liked by peers. The death of such teenagers often comes as a great surprise to their relatives and friends, because they were known to be such "good" young people. While perfectionism has been proposed as a risk factor for suicidal ideation (Hewitt et al., 1997), recent studies have failed to show that perfectionism, as distinct from anticipatory anxiety, is an independent predictor of suicide.

Although some adolescents-predominantly girls suffering from a major depressive disorder-appear to have thought about suicide for some time and will often have made some preparation for their death, most adolescent suicides appear to be impulsive (Lucas et al., 1995). The suicide is often preceded by a stress event, such as getting into trouble at school or with a law enforcement agency, a ruptured relationship with a boyfriend or a girlfriend, or a fight among friends. In many instances, these stress events can be seen as a byproduct of an underlying mental disorder.

It also appears that a suicide can be precipitated - in presumably already suicidal youth-by exposure to news of another person's suicide or by reading about or viewing a suicide portrayed in a romantic light in a book, magazine, or newspaper (Bollen and Philips, 1982; Gould and Shaffer, 1986; Hafner and Schmidtke, 1989).

About a third of suicides have made a previous known suicide attempt (Brent et al., 1999; Shaffer et al., 1996a). Previous attempts are more common in girls and among suicides suffering from a mood disorder at the time of their death. Suicide must be distinguished from autoerotic asphyxia, which is induction of oxygen deficiency to enhance sexual excitement and orgasm (Johnstone and Huws, 1997). However, autoerotic deaths in teenagers are rare (Shaffer et al., 1996a). When autoerotic deaths do occur, the victims often have other forms of psychopathology, such as depression and substance abuse (Sheehan and Garfinkel, 1988). It is possible, therefore, that some autoerotic deaths are misclassified suicides.

Most suicide pacts occur between married couples and/or other family members. They are most common in the middleaged and elderly population (Brown et al., 1995) and are very uncommon in young people. Shaffer et al. (1996a) noted only one suicide pact in 140 consecutive suicides occurring in the New York/New Jersey/western Connecticut area over a period of 2 years.

\section{RISK FACTORS FOR SUICIDE}

\section{Psychiatric Disorders}

Controlled studies of completed suicide suggest similar risk factors for boys and girls (Brent et al., 1999; Shaffer et al., 1996a), but with marked differences in their relative importance (Shaffer et al., 1996a).

Girls. The most significant risk factor is the presence of major depression, which, in some studies, increases the risk of suicide 20-fold (Shaffer et al., 1996a). The next most important risk factor is a previous suicide attempt, which increases the risk significantly. 
Boys. A previous suicide attempt is the most potent predictor, increasing the rate more than 30-fold (Brent et al., 1999; Shaffer and Craft, 1999). It is followed by depression, substance abuse (alcohol or drugs), and disruptive behavior (Brent et al., 1993b; Shaffer et al., 1996a).

Disruptive disorders are common in male teenagers who commit suicide. In the New York (Shaffer et al., 1996a) and Pittsburgh (Brent et al., 1999) studies, as many as one third of male suicides had evidence of conduct disorder. The disruptive disorder was commonly comorbid with a mood, anxiety, or substance abuse diagnosis. A number of mechanisms may account for the associations, including early deprivation or other childhood experiences that predispose to both depression and antisocial behavior, a temperamental predisposition to violent or impulsive behavior, or the secondary consequences of the numerous stresses that often occur in the lives of young people with a disruptive disorder.

Although the rate of suicide is greatly increased in schizophrenia, because of the rarity of the condition it accounts for very few suicides in the child and adolescent age group. However, mental health professionals who care for individuals with schizophrenia should be aware of their greater risk for suicide.

\section{Psychosocial Stressors}

Stressful life events often precede a suicide and/or suicide attempt (de Wilde et al., 1992; Gould et al., 1996). They are rarely a sufficient cause in suicide, and their importance lies in their action as precipitating factors in young people who are at risk by virtue of their psychiatric condition.

Controlled studies (Gould et al., 1996; Hollis, 1996) indicate that low levels of communication between parents and children may act as a significant risk factor. While family discord, lack of family warmth, and disturbed parent-child relationship are commonly associated with child and adolescent psychopathology (violent behavior, mood disorder, alcohol and substance abuse disorders) (Brent et al., 1994b; Pfeffer et al., 1994), these factors do not play an especially important role in suicide (Gould et al., 1996).

\section{Cultural Factors}

Until recent years, suicide was much more common among whites than among African Americans at all ages. However, since 1987, the difference in rates between young African Americans and whites has narrowed (Shaffer et al., 1994). This is because the suicide rate in African-American and other minority males has increased rapidly, while the rate among whites has been steady or has declined. The suicide rates for male 15- to 19-yearolds in 1986 were 18.0 per 100,000 for whites and 7.1 per 100,000 for African Americans, but in 1996 the white male suicide rate declined to 16.3 per 100,000 and the African-American male suicide rate increased to 11.5 per 100,000 . The suicide rate for 15- to 19-year-old African-American males increased by $100 \%$ in this period, and the suicide rate for 20- to 24-year-old African-American males increased by 300\% (Shaffer et al., 1994). The ratio of African-American to white suicides has changed most in the central states, where the African-American rate had been lowest (Shaffer et al., 1994).

From 1979 to 1992, the Native American male adolescent and young adult suicide rate in Indian Health Service areas was the highest in the nation: 62.0 per 100,000 (Wallace et al., 1996).

A number of reasons have been offered to explain the increase in African-American suicide rates. These include increased access to firearms in African-American communities. However, firearm ownership has also increased among women, and this has not led to a similar increase in the female suicide rate (Murphy, 1998). Gould and colleagues (1996) found that African-American adolescents who committed suicide had a higher mean socioeconomic status than the general AfricanAmerican population. This led to the hypothesis that lowerclass, potentially more traditional and insular African-American communities might provide an undetermined protective factor. Other empirically unsupported explanations for the previous low rate of African-American suicides included better social support systems among African Americans and a greater sense of group adherence in a minority, multigenerational support, and the support provided by largely nonintegrated, insulated African-American communities (Gibbs, 1997; Shaffer et al., 1994). Theories contend that as these supports have weakened, the African-American suicide rate has risen. Yet another explanation has been that ethnic differences in religious beliefs account for the long-standing differences between AfricanAmerican and white rates, but that increased secularism in African-American youth has led to a reduction in AfricanAmerican/white differences (Neeleman et al., 1998). Levels of belief and fundamentalism (rather than the particular religion ascribed to) have been found to be associated with reduced acceptance of suicide (Neeleman, 1998) and increased optimism (Sethi and Seligman, 1993), and high levels of spiritual belief in the African-American community have been correlated with the particularly low suicide rate in particular AfricanAmerican communities (Martin, 1984; Neeleman et al., 1998). Martin (1984) and Neeleman et al. (1998) found that AfricanAmerican/white differences in suicidal ideation were no longer present after controlling for spirituality.

When spirituality is controlled for statistically, the risk factors for young African Americans appear similar to those for white youth (i.e., long-term depression, substance abuse, and living alone) (Juon and Ensminger, 1997). However, one should, in general, be cautious about generalizing about cultural influences. For example, while some Native American groups have a suicide rate that is more than 20-fold higher than the nation's average (May, 1987), others have suicide rates equal to or less than the national average. In some instances, this variability 
could be a function of contagion within isolated groups rather than a result of differences in beliefs, values, or practices.

\section{Facilitating Factors}

Why suicide should be an option for some young people and not for others remains a mystery. Some of the factors that may contribute to suicide include the following:

Maladaptive Attributional and Coping Styles. Perceptions of hopelessness, negative views about one's own competence, poor self-esteem, a sense of responsibility for negative events, and the immutability of these distorted attributions may contribute to the "hopelessness" that has been repeatedly found to be associated with suicidality.

Biological factors, specifically dysregulation of the serotonergic system, are common in adult suicides (Greenhill et al., 1995; Halperin et al., 1994; Kruesi et al., 1992; Mann, 1998; Mann and Stoff, 1997; Pfeffer et al., 1998; Pine et al., 1995). Dysregulation is manifest by low levels of serotonin metabolites in CNS fluids, low concentrations of presynaptic serotonergic receptors, and dense concentrations at postsynaptic receptors. These serotonin abnormalities have been localized to the ventrolateral prefrontal cortex and brainstem of suicide victims and attempters (in postmortem positron emission tomography studies as well as in vivo biological challenges) (Arango et al., 1997). This may be related to polymorphisms in the gene for tryptophan hydroxylase (Amsel and Mann, 2001). If this finding is confirmed, it could lead to the development of simple blood "tests" for suicidality. Serotonin appears to inhibit extreme fluctuations of mood and reactivity. The vulnerability to suicide of individuals with these biological abnormalities may be mediated by impulsivity and emotional volatility. As the ventral prefrontal cortex plays a role in behavioral inhibition, it is conceivable that serotonin irregularities in this area make it more difficult for a suicidal individual to control his or her suicidal impulses (Arango et al., 1997). Studies to demonstrate the precise behavioral correlates of

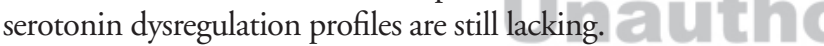

Adolescents are not exact biological counterparts of adults. Preliminary small-sample studies found that three quarters of adolescent suicide attempters had CSF 5-hydroxyindoleacetic acid (5-HIAA) concentrations that would indicate severe suicide risk in adults (Kruesi et al., 1988). In addition, these studies suggest that low CSF homovanillic acid concentrations might be more predictive in adolescents (Greenhill et al., 1995; Kruesi et al., 1988). Nordstrom and colleagues (1994) suggested that knowing the biological status of suicide attempters may have a practical value and that low CSF 5-HIAA concentrations examined shortly after a suicide attempt may differentiate between suicide attempters who will commit suicide or repeat the attempt within a year and those who will not.

Parental Psychopathology. A family history of suicidal behavior (Brent et al., 1996a; Gould et al., 1996), parental psychopathology, parental depression, and parental substance abuse (Brent et al., 1994b; Gould et al., 1996) are all additional risk factors for teen suicide. Whether these family histories indicate a genetic vulnerability or environmental stressors, or a combination of the two, is under study. Family history of suicidal behavior remains a significant risk factor when one statistically controls for effects of parental psychopathology (Brent et al., 1996a).

Social-Psychological Factors. There is an accumulation of evidence that supports the observation that suicide can be facilitated in vulnerable teenagers by exposure to real or fictional accounts of suicide (Gould, 2001a; Velting and Gould, 1997), including media coverage of suicide, such as intensive reporting of the suicide of a celebrity, or the fictional representation of a suicide in a popular movie or television show. The risk is especially high in the young (Gould, 1990; Gould et al., 1988; Gould and Shaffer, 1986), and it lasts for approximately 2 weeks (Bollen and Philips, 1982).

The phenomenon of suicide clusters, an excessive number of suicides occurring in close temporal and geographic proximity, is presumed to be related to imitation (Gould and Davidson, 1988). Suicide clusters often involve previously disturbed young people who were aware of another's death but who did not know the victim personally (Gould, 2001b). Clusters usually involve adolescents or young adults and account for only $1 \%$ to $5 \%$ of U.S. teen suicides (Gould et al., 1990a,b).

HIV-Positive Diagnosis and AIDS. It has been suggested that human immunodeficiency virus (HIV) infection increases the risk of suicide and suicidal behavior in adolescents and young adults (Coté et al., 1992; Kizer et al., 1988). However, Dannenberg et al. (1996) found no increase in suicide risk during a median follow-up period of 17 months in HIV-positive applicants for service in the United States military. Marzuk et al. (1997) found the proportion of New York City suicides who were HIV-positive (adjusted for demographic variables) was higher than the estimated proportion of HIV-positive individuals living in New York City. However, as the information was determined at autopsy, it was unknown whether all suicides were aware of their HIV status and whether they had other risk factors for suicide. More than two thirds of HIV-positive suicide victims had no HIV-related pathology at the time of autopsy, and the investigators concluded that the high HIV-positive rate among suicides could be accounted for by other common underlying risk factors such as substance abuse or alcoholism.

One hypothetical model for how these various risk factors fit together is illustrated in Figure 3.

\section{NONLETHAL SUICIDAL BEHAVIOR: EPIDEMIOLOGY}

Suicide attempts involve any behavior that is intended to end the child's or adolescent's life. Nonfatal suicidal acts by ingestion, with nonlethal intent, are sometimes referred to as parasuicide. It is estimated that each year, approximately 2 million U.S. adolescents attempt suicide, and almost 700,000 receive medical attention for their attempt (Centers for Disease Control and Prevention, 1998). 


\section{HOW DO SUICIDES OCCUR AND HOW CAN THEY BE PREVENTED?}

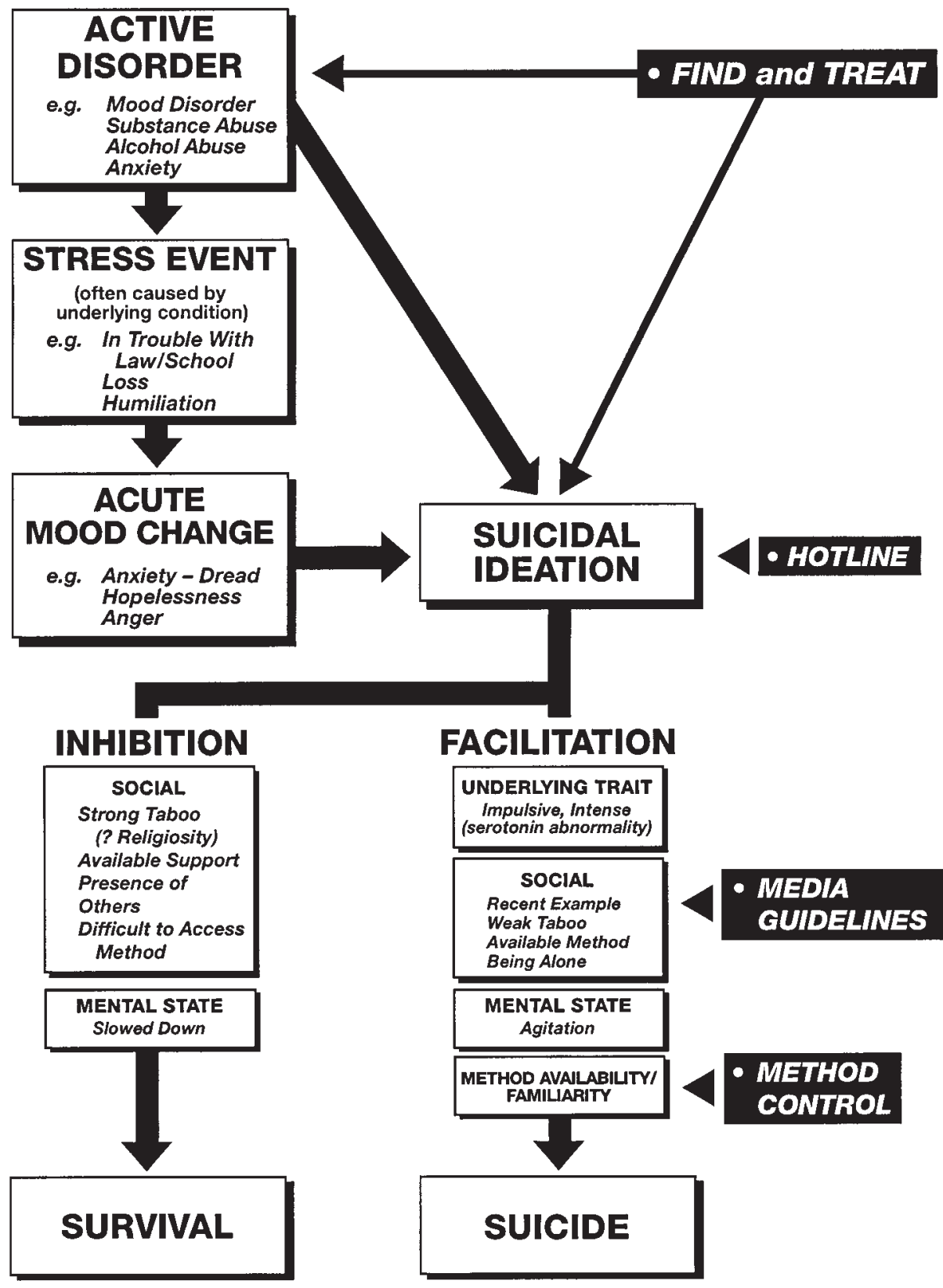

Fig. 3 This model suggests how suicide occurs and highlights types of targeted preventive interventions.

Suicide attempts in adolescence are approximately twice as common in females as males (Centers for Disease Control and Prevention, 1998). In the 1997 U.S. Youth Risk Behavior Survey of approximately 20,000 representational teenagers, suicide attempts were considerably more common in Hispanic females $(14.9 \%)$ than in either whites $(10.3 \%)$ or African
Americans (9.0\%). Attempts were also more common among Hispanic males (7.2\%) than among whites (3.2\%) or African Americans (5.6\%).

Suicidal ideation is very common among high school students, with approximately one in four females and one in six males having seriously considered suicide in a 12 -month 
period. Hispanic students of both sexes were significantly more likely than whites or African Americans to have seriously considered suicide, made a suicide plan, attempted suicide, or made an attempt requiring medical attention.

The reasons for the higher rate of suicidal ideation and attempt behavior in Hispanic youth are not known. In their longitudinal examination of the Chicago Woodlawn sample, Juon and Ensminger (1997) found risk factors for suicidal behavior in African Americans to be very similar to those found in whites (i.e., depression and substance use and a number of family variables).

\section{CLINICAL PRESENTATION OF SUICIDAL BEHAVIOR}

The spectrum of severity of suicidal behavior ranges from suicidal ideation, through suicide threats and suicide attempts, to completed suicide.

\section{Suicidal Ideation}

Suicidal ideation includes thoughts about wishing to kill oneself; making plans of when, where, and how to carry out the suicide; and thoughts about the impact of one's suicide on others. Not all young children appreciate that suicide may result in irreversible death. There is no definite milestone for understanding the irreversibility of death, which depends to a large extent on what the child has been taught at home and on the child's own experiences of death and illnesš. A child's appreciation of the finality of death should not necessarily influence the clinician in judging the seriousness of suicidal ideation. For example, a child who believes that someone who dies returns to life a few hours later may be prone to engage in self-harming behavior, not understanding the long-term consequences of the behavior.

\section{Suicide Threats}

Suicide threats are utterances made to others that indicate an intent to commit suicide. They may be accompanied by actions to initiate a suicide plan. In young children and adolescents, these are most commonly threats to jump out of a window (usually made when the child is near a window), to run into traffic, or to stab himself or herself.

\section{Methods of Attempt}

The large majority of known suicide attempts in the United States are by ingestions, most commonly of over-the-counter analgesics, but the incidence of acts such as hanging, which if not successful may not lead to a medical referral, is not known. Other common attempt methods include superficial cutting of the arms or neck, and, again, the prevalence of this is not known. Less common methods include attempts by the child or teenager to hang himself or herself, jump from a height, stab himself or herself, drown, or self-immolate. The choice of both attempt and completion method is largely determined by opportunity, but local customs seem to play a role, for there are quite markedand stable — national differences in preferred methods.

In assessing suicide-attempt behavior, attention is paid to the unusualness of the attempt method, its medical seriousness, how often it has been repeated, and the steps taken to prevent or promote discovery. Repeated attempts, attempts by unusual methods (i.e., other than ingestions or superficial cutting), and medically serious attempts are predictive of further suicide-attempt behavior and also seem to be predictive of ultimate death by suicide (Beck et al., 1974a) (Table 1).

\section{Risk Factors}

Risk factors for suicide attempts in both genders are mood or anxiety disorders or substance abuse. Panic attacks in girls and disruptive behavior in boys increase risk for suicidal ideation or attempt.

It is very likely that serious family disturbances increase the risk for attempted suicide. This can be inferred from the high incidence of suicide in abused children (Brown et al., 1999; Fergusson et al., 1996; Molnar et al., 1998; Silverman et al., 1996). Suicidality is also common in runaway teenagers (Deykin et al., 1985; Kaplan et al., 1997; Molnar et al., 1998; Shaffer et al., 1996b), who often have a history of previous child abuse. Child abuse is commonly associated with various types of psychopathology and substance abuse, and it is not clear whether the high prevalence of suicidality is a specific consequence of that psychopathology or is more specifically related to a history of abuse. Physical and sexual abuse appear to increase the risk of suicide attempt even when other factors are controlled for (Fergusson et al., 1996; Statham et al., 1998).

Regardless of the mechanisms, a clinician who suspects that a child or adolescent has been abused should assess past and present suicidal ideation or behavior. Conversely, because the attributable risk is quite high (between $15 \%$ and $20 \%$ of female attempters have a history of abuse), suicide attempters should routinely be asked about previous or current experience of physical and sexual abuse.

While there is no evidence that minority sexual orientation is more common in completed teen suicides than in controls, there is strong evidence that gay, lesbian, and bisexual youth of both sexes are significantly more likely to experience suicidal ideation and attempt suicide. Research in five sizable community samples has demonstrated increased risk (Faulkner and Cranston, 1998; Fergusson et al., 1999; Garofalo et al., 1998; Lock and Steiner, 1999; Remafedi et al., 1998). The increased risk for suicidal ideation and attempt behavior ranges from 2-fold (Faulkner and Cranston, 1998) to 7-fold (Remafedi et al., 1998). Gay, lesbian, and bisexual youths were also significantly more likely to make attempts requiring medical attention. Gay, lesbian, and bisexual youths were shown in these studies to carry a number of risk fac- 
tors for suicidal behavior, including high rates of drug and alcohol use, and were more likely to partake of substances earlier and more frequently. Gay, lesbian, and bisexual youth were also more likely to be bullied and victimized at school. The degree of association between sexual orientation and youth suicidal behavior requires further study to determine effects when other risk factors, such as alcohol or substance use and family difficulties, are controlled for statistically.

\section{Differences Between Completed and Attempted Suicide}

Most of our knowledge about the clinical features of suicide attempters and the methods used by suicide attempters is drawn from cases seen in emergency rooms and clinics. The kind of case that presents most commonly is a 15- to 17-year-old girl who has taken a small- or medium-sized overdose of a readily available medication, most commonly an over-the-counter analgesic or available medication taken by another family member. The behavior is usually impulsive and occurs in the context of a dispute with family or boyfriend or girlfriend.

We do not know how typical this profile is, because it is only very recently that investigators have started to collect information from community-based studies. These studies indicate that the suicide attempt rate among boys is considerably higher in the community than among patients who present in the emergency room. One of the reasons for this may be that the female-preferred method-a nonlethal ingestion-does not take immediate effect and is treatable. If the patient changes his or her mind or admits to the attempt, he or she will nearly always seek medical treatment for the medical effects of the overdose. However, it seems likely that many boys attempt to hang themselves and fail, and only rarely do they then seek or need medical treatment. Our knowledge of the differences between referred and nonreferred suicide attempters is limited largely to demographic information, and clinical differences still need to be described in greater detail.

Studies that have compared completed suicides with suicide attempts have examined clinical cases and, after controlling for gender, they have failed to show significant differences. However, too much should not be made of these negative findings, because serious attempters requiring inpatient care are unlikely to be representative of suicide attempters in general.

There have been very few risk-factor comparisons between completed and attempted suicides (Brent et al., 1988; Gould et al., 1998; Shaffer et al., 1996a). Brent et al. found attempters less likely than completers to be bipolar, have a firearm in the home, have high suicidal intent, or have combinations of mood and nonmood disorders. When suicide attempters and suicides are compared, the attempters need to be drawn from a geographically defined nonreferred sample, similar to the type usually used in psychological autopsy studies of suicides. Two attempter studies of that type (Andrews and Lewinsohn, 1992; Gould et al., 1998) found broadly similar diagnostic profiles to those reported in suicide completers (Shaffer et al., 1996a; Brent et al., 1993a). Failure to find robust differences between the two groups may reflect the requirement in some studies that the attempted-suicide controls be people who made "serious attempts."

\section{NATURAL HISTORY}

Little is known about the natural history of suicidal behavior, but early onset of suicidal behavior in prepuberty predicts suicidal behavior in adolescents (Pfeffer et al., 1991, 1993) and early onset of major depressive disorder is associated with suicidal behavior in adolescents (Kovacs et al., 1993) and adults (Harrington et al., 1994; Rao et al., 1993). Attempts to predict at the time of the first attempt which adolescents are likely to repeat their suicidal behavior have not been successful (Goldston et al., 1996; Stein et al., 1998).

\section{DEVELOPMENTAL FEATURES}

Developmental factors are significant mediators of the clinical presentation of suicidal behavior in children and adolescents and are reflected in the epidemiology of suicidal behavior. Suicidal behavior has been reported among preschool children despite their immature cognitive appreciation of the finality of death (Pfeffer and Trad, 1988; Rosenthal and Rosenthal, 1984). Various suicidal methods are used by suicidal children and adolescents, but the younger the child, the less complex and the more easily available are the methods used to enact suicidal impulses. Differences between suicidal ideators and suicide attempters are least marked for younger children (Carlson et al., 1994). For example, suicidal ideation and suicide attempts among prepubertal children both predict suicide attempts in adolescence (Pfeffer et al., 1993). Social adjustment problems of young suicide attempters consist mainly of disturbed intrafamilial relationships in prepubertal children, while peer-related conflicts are the most common among adolescents.

The modal ages of onset of the psychiatric symptoms and disorders that increase risk for suicidal behavior in adolescents (such as major depression, substance abuse, bipolar disorder, schizophrenia, and personality disorders) vary across adolescence, with all being more common in older adolescents. This may be the reason for the relative rarity of suicide in childhood and adolescence. Suicide becomes increasingly common with age, reaching a peak between the ages of 19 and 23 years. Adult suicide attempters are eight times more likely than adolescent attempters to commit suicide during the first 312 years after discharge from a psychiatric hospital (Safer, 1997).

\section{ASSESSMENT}

Assessment of suicidal patients requires an evaluation of the suicidal behavior and determination of risk for death or repetition as well as of the underlying diagnosis or promoting factors. 


\section{ASSESSMENT OF THE ATTEMPT}

Determine the type of method used in the suicide attempt (more unusual attempts, i.e., method other than cutting or small ingestion, carry a worse prognosis), the potential medical lethality (not always a reliable predictor; some seriously suicidal children and teenagers are poor judges of lethality), the degree of planning involved, and the degree to which the chance of intervention or discovery was minimized (signifying higher intent). Previous suicide attempts make a further attempt more likely; a pervasive and frequent degree of current suicidal ideation also denotes greater seriousness and a greater likelihood of an associated mental illness. Availability of firearms or lethal medications should be ascertained, and a recommendation for removal or more secure storage should be made (Brent et al., 1988) as an imperative part of assessment.

\section{ASSESSMENT OF THE SUICIDAL IDEATOR}

The key question is whether the child or adolescent is contemplating or has attempted suicide without anyone's knowledge. Children and adolescents may be asked the following diagnostic questions (Jacobsen et al., 1994):

- "Did you ever feel so upset that you wished you were not alive or wanted to die?"

- "Did you ever do something that you knew was so dangerous that you could get hurt or killed by doing it?"

- "Did you ever hurt yourself or try to hurt yourself?"

- "Did you ever try to kill yourself?"

- "Did you ever think about or try to commit suicide?"

Evaluating the presence and degree of süicide intent is a complicated matter. Suicide intent involves a balance between the wish to die and the wish to live (Beck et al., 1974a). Some aspects of this address severity of the behavior, the efforts made to conceal the behavior and avoid discovery, and the formulation of specific plans (e.g., "Did you do anything to get ready to kill yourself? Did you think what you did would kill you?"). However, children and adolescents systematically overestimate the lethality of different suicidal methods, so that a child or adolescent with a significant degree of suicidal intent may fail to carry out a lethal act.

Another approach in assessing suicidal intent is to evaluate motivating feelings, for example, the wish to gain attention, to effect a change in interpersonal relationships, to rejoin a dead relative, to avoid an intolerable situation, or to get revenge. If these motivations have not been satisfied by the time of the evaluation, serious suicidal intent may still be present.

\section{RISK FACTORS FOR REPEATED SUICIDE ATTEMPT OR SUICIDE}

Factors that increase the risk of subsequent suicide attempts and/or suicide after a recent attempt are shown in Table 1 and include male gender, increasing age, living alone (i.e., run- away, homeless, or isolated), having made previous attempts, attempts with a method other than by ingestion or superficial cutting, and having taken steps to avoid detection. There is also a greater short-term risk of suicide if the current mental state is abnormal.

\section{ASSESSMENT OF THE UNDERLYING CONDITIONS}

The conditions that lead to suicidal behavior include psychiatric diagnosis; social or environmental factors such as isolation, anger, and stress; cognitive distortions that accompany depression, particularly hopelessness, which may also be an indicator of treatment dropout (Brent et al., 1997); and inappropriate coping styles (e.g., impulsivity or catastrophizing). A history of family psychopathology, especially of suicidal behavior, bipolar illness, physical or sexual abuse, or substance abuse, may give an indication of risk and of areas that will require intervention (Fergusson and Lynskey, 1995a,b; Pfeffer et al., 1994). Family discord and other life-event stresses involving interpersonal relationship problems also require assessment.

Psychiatric diagnoses that are commonly associated with suicidal behavior include depression, mania or hypomania, mixed states or rapid cycling, or substance abuse. Patients who are irritable, agitated, delusional, threatening, violent, deluded, hallucinating, or voice a persistent wish to die pose a greater short-term risk.

A history of rapid mood shifts, from brief periods of depression, anxiety, and rage, to euthymia and/or mania, which may be associated with transient psychotic symptoms, including paranoid ideas and auditory or visual hallucinations, has been held to be strongly associated with a risk for further suicide attempts. Diagnosing such adolescents is complex, and clinicians often use various diagnoses, including major depressive disorder with psychotic features, bipolar disorder, schizoaffective disorder, and borderline personality disorder, to characterize adolescents with this broad array of symptoms.

Recurring suicidal behavior has been associated with hypomanic personality traits (Klein et al., 1996) and cluster B personality disorders (Brent et al., 1993a, 1994a). The personality disorder that is most often diagnosed is borderline personality disorder (Corbitt et al., 1996). The DSM-IV criteria for this disorder include onset in early adulthood, repeated suicide attempts, nonlethal forms of self-injury, and a pervasive pattern of impulsivity which, after controlling for a lifetime history of depression and substance abuse, appears to be strongly associated with suicidality (Brodsky et al., 1997). Other criteria include unstable mood, unstable interpersonal relationships (that may alternate between idealization and denigration), varying concepts of self (which oscillate between grandiosity and worthlessness), dissociative symptoms, irritability, and behavior that, while pleasurable, can also be self-damaging (e.g., excessive spending, impulsive sexual activity, dangerous driving). Many of these symptoms are also features of bipolar ill- 
ness and other mood disorders, and whether or not borderline personality disorder is a form of bipolar or other mood disorder remains an open question.

Gathering information from multiple sources and by varied developmentally sensitive techniques is essential in evaluating suicidal risk indicators. This may include interviews, play and behavior observation, and use of standard, reliable, valid rating scales. The reliability and validity of interview reporting of children and adolescents may be affected by their level of cognitive development, which may influence their reports of time and cause, and by the type and intensity of emotions and severity of psychological distress at the time of interview, which may influence their memory of suicidal intent and their understanding of the relationship between their emotions and behavior (Carlson et al., 1994; Jacobsen et al., 1994). Confirmation of the child's or adolescent's suicidal behavior can be obtained from information gathered by interviewing others who know the child or adolescent. However, there is often a disparity between child and parent reports, with both children and adolescents being more likely to tell of suicidal ideation and suicidal actions than their parents (Brent et al., 1986).

\section{SPECIALIZED SUICIDE SCALES AND OTHER INSTRUMENTS}

Self-administered suicide scales are useful for screening normal, high-risk, and patient populations. They cannot substitute for a clinical assessment, and their tendency is to be oversensitive and underspecific. At this point, suicide scales alone do not have a predictive value / A child or adolescent whois positive on a suicide scale should always be assessed clinically. Most scales have not been tested adequately in a child or adolescent population (see Garrison et al., 1991, and Goldston, 2000, for more information on individual scales). Table 3 lists scales measuring suicidality, intent, or potentiality.

\section{TREATMENT}

\section{PRINCIPLES OF TREATMENT}

The successful treatment of suicidal children and adolescents depends on a number of factors, with safety considerations being of overriding importance (Pfeffer, 1990, 1997).

Because of the need to respond to a suicidal crisis, treatment should ideally be provided within a "wrap around" servicedelivery system that includes resources for inpatient, shortand long-term outpatient, and emergency intervention (Rotheram-Borus et al., 1996c).

\section{ACUTE MANAGEMENT}

The child or adolescent who has attempted suicide should be hospitalized if his or her unstable condition makes behavior unpredictable, indicating at least short-term serious risk.
Mental status features predictive of short-term difficulty include the inability to form an alliance with the clinician, a lack of truthfulness or inability to discuss or regulate emotion and behavior, psychotic thinking, current intoxication from drugs or alcohol, or multiple previous serious suicide attempts. Diagnostic features indicating the need for hospitalization include major depressive disorder with psychotic features, rapid cycling with irritability and impulsive behavior, psychosis with command hallucinations, and alcohol or substance abuse. Social factors affecting the decision to hospitalize a child or adolescent include a lack of sufficient environmental support to help stabilize the child's or adolescent's psychiatric state.

The clinician should ask himself/herself whether the patient can form an alliance to report suicidal intent or suicidal plans. Can the clinician identify and decrease potential sources of noncompliance, provide adequate family psychoeducation to limit family conflicts and aberrant communication, reduce social-skill and problem-solving deficits, and focus on cooccurring psychopathology (Berman and Jobes, 1991; Brent, 1997; Brent and Perper, 1995; Piacentini et al., 1995)? Being aware of one's limitations in prediction and influence over the family and patient will promote a cautious approach.

\section{EMERGENCY OR CRISIS-SERVICE INTERVENTION AND TRIAGE DECISIONS}

Children and adolescents with acute suicidal ideation or suicide attempts are frequently first evaluated and treated in an emergency service. It is here that the mental health professional provides the important triage function of referring suitable patients for subsequent treatment. Children and adolescents should never be discharged from the emergency service without the child's or adolescent's caretaker having verified the child's or adolescent's account (Table 4). The caretaker also should be seen to discuss making firearms and/or lethal medications inaccessible to the child (Kruesi et al., 1999). There is empirical evidence that unless this discussion is held, parents will not, on their own initiative, take the necessary precautions (McManus et al., 1997). Parents are more willing to secure firearms than to remove them. Limiting the adolescent's access to alcohol or other potentially disinhibiting substances should also be discussed with the adolescent and family. Before discharge, the clinician must have a good understanding of the amount of support that will be available for the child or adolescent if discharged to home. The clinician should recognize that treatment recommendations are more likely to be followed if they match the expectations of the family, if they are economically feasible, and if the parent is well and available enough to support attendance. The family's experience in the emergency room may also color the referral process (Rotheram-Borus et al., 1996a,b).

Rotheram-Borus et al. (1996b) described a brief emergency room crisis intervention procedure for adolescent attempters that resulted in improved compliance for at least the first out- 


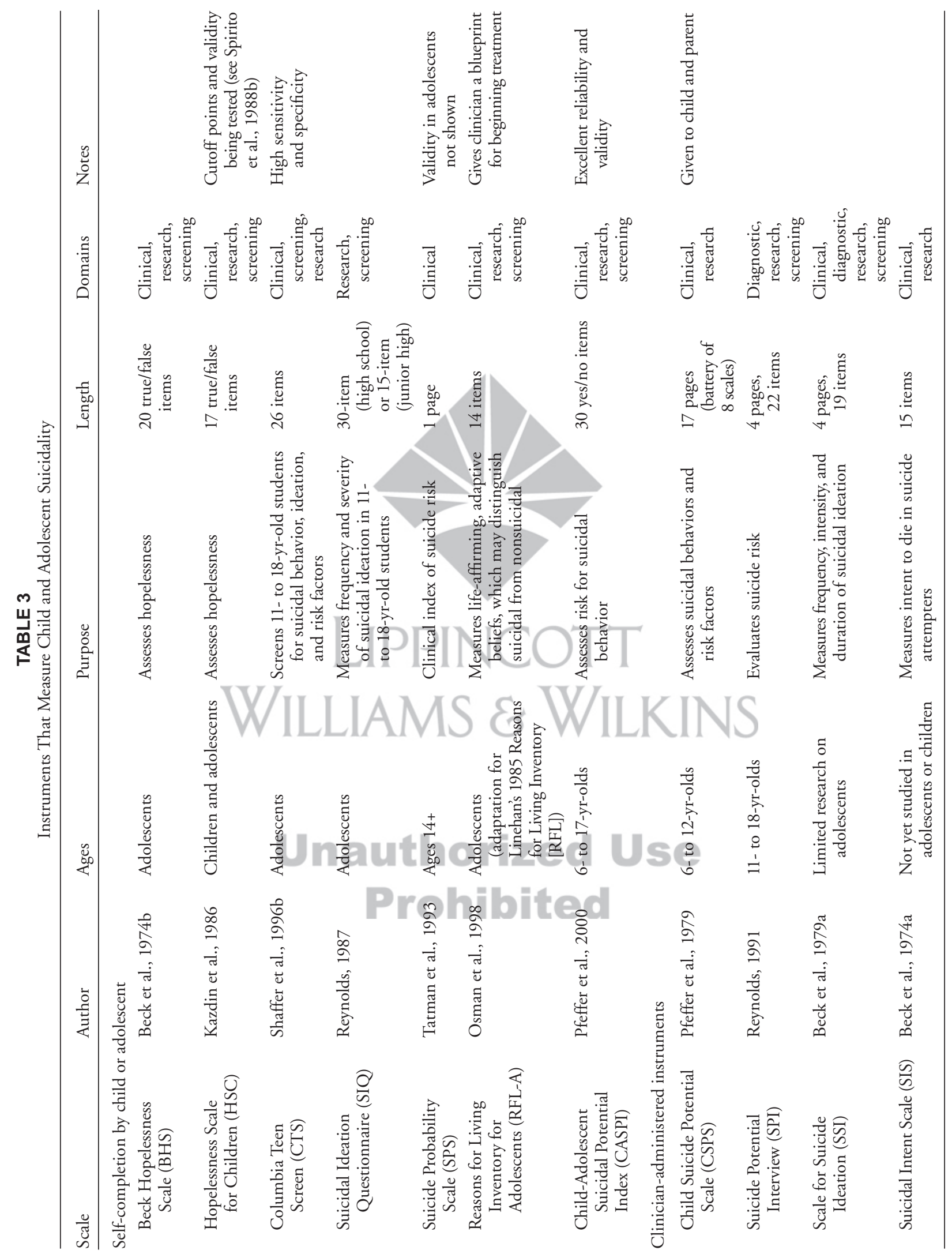




\section{TABLE 4}

Checklist Before Discharging an Adolescent Who Has Attempted Suicide

Before discharging a patient from the ER or crisis center, always:

- Caution patient and family about disinhibiting effects of drugs or alcohol

- Check that firearms and lethal medications can be effectively secured or removed

- Check that there is a supportive person at home

- Check that a follow-up appointment has been scheduled

patient follow-up visit. The aim of the intervention was to provide a good experience between the family and emergency service staff, set realistic expectations about follow-up treatment, and obtain a commitment from the adolescent suicide attempters and their relatives to return for further evaluation. It included a series of emergency room staff training sessions to reduce staff perceptions that the family was to blame for the teenager's behavior and to encourage staff to explain emergency service procedures to the patient. A videotape was shown to the attempter and family to increase their understanding of adolescent suicidal behavior and its treatment. Finally, a family treatment session was provided by a crisis therapist who negotiated a contract with the suicidal adolescent and family and who served some case management functions between the family and the follow-up treatment provider. The research was not able to identify which of these components led to an increase in initial compliance.

There should always be a detailed discussion with the patient and family about the specific issues or situations that might promote further suicidal behavior if stress is unavoidable and the type of coping behavior that can be used to obviate a further attempt. Helping the family to identify potential precipitants, beginning to problem-solve on how to prevent reoccurrence, is really the beginning of treatment. If the patient and family cannot effectively do this, it becomes a matter of concern. A written or verbal "no-suicide contract" is commonly negotiated at the start of treatment in the hope that it will improve treatment compliance and reduce the likelihood of further suicidal behavior (Brent, 1997; Rotheram, 1987). The no-suicide contract can be used as a "probe" to understand the patient's and family's ability to institute change. However, the clinician should know that there have been no empirical studies that have evaluated the efficacy of a contract (Reid, 1998). The usual form of a contract is that the child or adolescent should promise not to engage in suicidal behavior and should inform the parents, therapist, or other responsible adult if he or she has thoughts of suicide or develops plans to commit suicide (Simon, 1991). It is hoped that a contract will increase the patient's and family's commitment to treatment, but it should never substitute for other types of intervention. If there is a disturbance of mental state, the clinician should never rely on a no-suicide contract (Egan et al., 1997; Fergusson and Lynskey, 1995b).
Limitations must be considered when using a no-suicide contract (Miller et al., 1998). It should be used only if a comprehensive assessment of the suicidal patient's mental state and a consideration of the developmental state indicate that the patient understands the commitment. It should not be seen as more than an adjunct to the management of patients with low intent. Even if the patient agrees to such a contract, suicide risk may persist. It should also be appreciated that a no-suicide contract may lessen a patient's communication of stress and dysphoria, decrease the potential for developing a therapeutic alliance, and impair risk management. Coercive communications, such as "unless you promise not to attempt suicide, I will keep you in the hospital or tell your parents about your behavior," should be avoided, because this may encourage deceit and defiance.

Treatment compliance may be improved by offering definite, closely spaced follow-up appointments, being flexible in arranging appointments if a crisis should arise, and reminding the family and patient by telephone or note about the next appointment. If an appointment is missed, the patient and parent should be contacted. Hopeless and depressed children and adolescents, who may be not be able to commit to a lengthy treatment process, may be better engaged by offering short-term treatment plans with defined intervention goals. While offering confidentiality for some issues, it is essential that the clinician communicate to the patient that if the clinician feels that suicidal thinking or behavior is imminent, such information will be shared with the parents.

\section{INPATIENT CARE AND PARTIAL HOSPITALIZATION}

There is no evidence that exposure to other suicidal psychiatric inpatients will increase the risk of suicidal behavior (King et al., 1995). Determining when a patient is ready for discharge from the hospital or crisis center will usually include an evaluation of the severity of existing suicidal ideation and intent. Implicit coersions, e.g., telling the patient that he/she will not be discharged until he/she can state that he/she is not suicidal, should be avoided. Attention to clearly dysfunctional family patterns or parental psychiatric illness may improve the child's or teenager's later outpatient care (King et al., 1997).

Partial hospitalization offers intensive multidisciplinary treatments and skilled observation and support. It can be a good alternative to acute psychiatric hospitalization if the child or adolescent is considered to be disturbed but containable in a supportive home or other residential setting. Partial hospitalization may provide more time than acute hospitalization to stabilize the emotional condition and address environmental stresses and problems. It may be used as a step-down from acute psychiatric hospitalization.

\section{OUTPATIENT TREATMENT}

Outpatient treatment should be used when the child or adolescent is not likely to act on suicidal impulses, when there is 
sufficient support at home, and when there is someone who can take action if the adolescent's behavior or mood deteriorates.

\section{SPECIFIC PSYCHOTHERAPIES}

Suicidal children and adolescents report feeling intense, painful, and distressing depression and worthlessness; anger; anxiety; and a hopeless inability to change or find a solution to frustrating circumstances (Kienhorst et al., 1995; Ohring et al., 1996). They may respond impulsively to their sense of desperation by attempting to commit suicide. Psychotherapeutic techniques aim to decrease such intolerable feelings and thoughts and to reorient the cognitive and emotional perspectives of the suicidal child or adolescent (Kernberg, 1994; Spirito, 1997). Working with suicidal children and adolescents is best done by a clinician who is available to the suicidal patient and family, has skill and training in managing suicidal crises, relates to the patient in an honest and consistent way, can objectively understand the suicidal patient's attitudes and life problems, and conveys a sense of optimism and activity (Katz, 1995; Pfeffer, 1990). Given these personal attributes, the therapist may use various models of psychotherapy, although relatively few empirical studies have evaluated their efficacy.

\section{Cognitive-Behavioral Therapy}

Suicidal children and adolescents often experience negative cognitions about themselves, their environment, and their future. Cognitive-behavioral therapy (CBT) has been shown to be an effective intervention for depressive symptoms (Clarke et al., 1999; Elkin et al., 1989; Shè ēt al., 1992; Weissman, 1979). Experience with teenagers is much more limited. In a single set of studies, short-term CBT appeared to be more effective than family or supportive therapy (Brent et al., 1997) in depressed teenagers. But after 2 years, differences between the groups were no longer apparent (Birmaher et al., 2000). The efficacy of CBT in suicidal adolescents has not yet been examined, but in the above studies all therapies reduced suicidal ideation.

Brent and colleagues created a CBT treatment manual (Brent and Poling, 1989, revised 1997), modifying the approach of Beck and colleagues (1979b) for depressed adolescents. The treatment comprised 12 to 16 weekly sessions followed by a 6month booster phase of monthly or bimonthly sessions. Parents and adolescents received a psychoeducational manual about mood disorders and their treatments and were offered a session just to discuss these issues. The active intervention was described as a collaborative "guided discovery" to monitor and modify automatic thoughts, assumptions, and beliefs (Brent, 1997). Concrete examples were used to illustrate the cognitivebehavioral treatment model that involves exploring concerns about autonomy and trust, cognitive distortions, and negative self-concepts, attributions, and cognitions.

Since suicidal individuals are thought to often have difficulty in communicating and negotiating their needs and wishes
(McLeavey et al., 1994) and to frequently resort to passive avoidant coping strategies (Adams and Adams, 1991), Brent's treatment model encouraged more assertive and direct methods of communicating, as well as increasing the teenager's ability to conceptualize alternative solutions to problems. Meetings with parents were sometimes held to augment the treatment. Brent (1997) advocates adjunctive use of psychopharmacology if depressed adolescents have not improved after 4 to 6 weeks of cognitive-behavioral treatment.

Brent's study provides no evidence of the efficacy of CBT for teenagers who had made a suicide attempt, who were not included in this study. However, the intervention was reported to be as effective as systemic family therapy and nondirective supportive therapy in reducing suicidal ideation in depressed adolescents (Brent et al., 1997) during the 12- to 16-week treatment period.

\section{Interpersonal Psychotherapy}

Suicidal behavior in children and adolescents is frequently associated with interpersonal conflict, and treatment of this may reduce suicidal risk.

Interpersonal psychotherapy (IPT) is a time-limited psychotherapy that addresses interpersonal problems, which are categorized into issues of loss, interpersonal role disputes, role transitions, and interpersonal deficits. It was originally developed for major depression (Klerman et al., 1984) and was designed to be administered over 12 to 16 weeks. Mufson and Moreau have modified it for use with depressed adolescents (Mufson et al., 1999) and found it more effective than a control therapy. The treatment may be appropriate for suicidal depressed adolescents with interpersonal problems.

IPT focuses on current interpersonal relationships and on the immediate social context. Unlike CBT, which addresses the distortions of thinking that may provoke maladaptive behavior, IPT focuses on the style and effectiveness of interpersonal interactions. The adolescent's treatment is administered weekly over 12 weeks. Frequent telephone contacts are maintained with adolescent patients, and parents are often involved.

The initial phase involves an evaluation of symptoms, diagnosis, and history of interpersonal relationships. Special attention is paid to changes in relationships immediately prior to the onset of depressive symptoms. The therapist educates the patient about the symptoms of depression and places the symptoms within a framework of interpersonal distress, such as reactions to loss, interpersonal role disputes (conflicts with a significant other person), role transitions (change in life status, such as change of grade or school, moving, change in a relationship), and interpersonal deficits (lack of social skills that lead to problems starting and sustaining interpersonal relationships). Some of the interpersonal issues for adolescents that are addressed by IPT-A include separation from parents, conflicts with parental authority, development of close relationships with 
members of the opposite sex, initial experience with death of a relative or friend, and peer pressures. Specific issues of adolescents living in single-parent households are addressed (Mufson et al., 1993), and the family may be included in the treatment.

The middle phase addresses the patient's own interpersonal problems. The therapist supports efforts to decrease the patient's pessimism and efforts to achieve new solutions to interpersonal dilemmas. The treatment emphasizes options for change that had been precluded by symptoms of depression.

The termination phase supports the patient's newly achieved and recognized independence in managing interpersonal concerns. It aims to assist the patient in recognizing and diminishing effects of future depressive symptoms.

Mufson and colleagues (1993) caution that IPT for adolescents was developed for nonpsychotic, nonsuicidal depressed adolescents. However, it is a useful treatment for addressing the adolescent's use of suicidal behavior as a method of communicating anger, distress, or resolving conflict, and its ability to help adolescents with suicidal ideation will depend on the adolescent's ability to establish a therapeutic alliance and commit to informing the therapist about suicidal preoccupations and intent and going to an emergency service if necessary.

\section{Dialectical-Behavioral Therapy}

Dialectical-behavior therapy (DBT) is the only form of psychotherapy that has been shown in a randomized controlled trial to reduce suicidality in adults with borderline personality disorder (Linehan, 1993a,b). This treatment is based on a biosocial theory in which suicidal behaviors are considered to be maladaptive solutions to painful negative emotions (Linehan, 1993a) but that also have affect-regulating qualities and elicit help from others (Linehan, 1993a).

The treatment involves developing problem-oriented strategies to increase distress tolerance, emotion regulation, interpersonal effectiveness, and the use of both rational and emotional input to make more balanced decisions (Linehan, 1993b). It usually involves individual and group sessions over the course of a year.

Recently, a modified and manual-based form of this treatment was used with suicidal adolescents with a diagnosis of borderline personality (Miller et al., 1997). DBT for adolescents (DBT-A) required the participation of a relative in the skills training group who was charged with improving the home environment and teaching other relatives to model and reinforce adaptive behaviors for the adolescent. DBT-A has been reduced from 1 year to two 12-week stages, covers fewer skills, and uses simpler language for skills training. In a nonrandomized comparative-treatment study with adolescents who were suicidal and diagnosed as borderline, there was a suggestion that DBT-A is acceptable to teenagers and reduces rates of psychiatric hospitalization (Miller et al., 1997).

The treatment comprises four components or modules: (1) a Core Mindfulness Skills module to diminish identity confusion and self-dysregulation; this includes teachings of Zen meditation to enhance emotional control; (2) an Interpersonal Effectiveness Skills module to enable interpersonal problem-solving through assertiveness training and to make the adolescent more aware of his or her goals in an interpersonal situation; (3) a Distress Tolerance module to reduce impulsivity by teaching acceptance and tolerance of painful situations with self-soothing and distraction from pain and by generating ideas about the positive and negative aspects of painful situations; and (4) an Emotion Regulation Skills module to identify emotions, reduce emotional vulnerability, and increase positive events.

Individual therapy is given weekly and focuses on reviewing a weekly diary documenting suicidal and self-destructive behavior, behaviors that interfere with treatment and quality of life, and use of new skills. The therapist conducts a behavioral analysis of each behavior problem with the goal of understanding its function and the situations that provoked it, identifying constructive solutions, and avoiding problems. During the first 12 weeks of treatment, telephone consultations with the therapist include discussions about skills that may be useful to decrease suicidal behaviors, report positive behaviors and events, and resolve conflicts with the therapist.

In the second 12 weeks of treatment, patient consultation groups focus on adolescents helping each other to utilize skills to cope with life circumstances.

\section{Psychodynamic Psychotherapy}

Conflict resolution is a basic issue in psychodynamic psychotherapy. It aims to resolve internal conflicts related to early experiences with rejection, severe discipline, and abuse. It also aims to improve self-esteem by enabling suicidal children or adolescents to become more self-reliant and less inhibited by the belief that they are responsible for creating their problematic circumstances. There are no studies that address the efficacy of this approach, which is probably the most commonly administered form of therapy and seems to encourage long-term involvement by the child or adolescent patient.

\section{Family Therapy}

As indicated above, family discord, poor communication, disagreements, lack of cohesive values and goals, and irregular routines and activities (Miller et al., 1992) are common in suicidal children and adolescents, who often feel isolated within the family. Some have suggested that they view themselves as expendable to the family and that this is a motivating force for self-annihilation (Miller et al., 1992; Pfeffer, 1986; Sabbath, 1969). Family intervention may decrease such problems, enhance effective family problem-solving and conflict resolution, and reduce blame directed toward the suicidal child or adolescent. Family-based cognitive therapy aims to reframe the family's understanding of their problems, to alter the family's maladaptive problem-solving techniques, and to encourage 
positive family interactions (Rotheram-Borus et al., 1994). Harrington et al. (1998) found that a time-limited home-based intervention for suicidal children and adolescents had limited efficacy for children and adolescents without major depressive disorder. Psychoeducational approaches can help parents clarify their understanding of childhood and adolescent suicidal behavior, identify changes in mental state that may herald a repetition, and reduce the extent of expressed emotion or anger (Brent et al., 1993d). The clinician can harness the power of the family to help restrict access to lethal medication and firearms and to convey the importance of treatment.

\section{PSYCHOPHARMACOLOGICAL INTERVENTIONS}

In meta-analyses of adult studies, Tondo and colleagues (1997) found that lithium maintenance treatment greatly reduces (8.6-fold) the recurrence of suicide attempts in adults with bipolar or other major affective disorders. Furthermore, when lithium is discontinued there is a 7-fold increase in the rate of suicide attempts and a 9-fold increase in the rate of suicide. Tondo et al. noted that the effects of lithium on reducing suicidal risk may be unique and may be due to its central serotonin-enhancing qualities. However, lithium prescriptions for children and adolescents require careful third-person supervision, as overdoses may be lethal.

Other mood stabilizers, such as valproate and carbamazepine, are also widely used to treat bipolar disorders in children and adolescents, although their efficacy has yet to be empirically demonstrated. However, as with adults, depressed suicidal children and adolescents with a history of bipolar disorder should first be treated with a mood stabilizer before receiving an antidepressant.

If lithium efficacy is eventually shown in adolescents, research will also be needed to determine the length of time necessary to treat suicidal children and adolescents. Psychopharmacological treatment can also be given for the associated disorders that are frequently present, although there is no evidence that this reduces the risk of later completed or attempted suicide. Furthermore, one must be careful about the risk of inducing suicidal ideation or behavior through psychopharmacological activation or disinhibition.

Studies in depressed adults have found that selective serotonin reuptake inhibitors (SSRIs) reduce suicidal ideation (e.g., Letizia et al., 1996) and separately reduce the frequency of suicide attempts in nondepressed patients with cluster B personality disorders and a history of suicide-attempt behavior. In a controlled trial of the depot neuroleptic flupenthixol, Montgomery and Montgomery (1982) noted a significant reduction in suicideattempt behavior in adults who had made numerous previous attempts. Similar studies have yet to be conducted on adolescents, although trials of SSRIs in depressed adolescents indicate that these drugs are safe and effective in treating adolescent depression (Emslie et al., 1997; Ryan and Varma, 1998). Because SSRIs, such as fluoxetine, appear to be more effective in treating adolescent depression (Emslie et al., 1997) than tricyclic antidepressants (Ryan and Varma, 1998) in placebo-controlled methodologically appropriate studies, it is reasonable to regard SSRIs as a first-choice medication for suicidal children and adolescents (see also the American Academy of Child and Adolescent Psychiatry's Practice Parameters for the Assessment and Treatment of Children and Adolescents With Depressive Disorders, 1998). In contrast to the highly lethal potential of tricyclic antidepressants when taken in overdoses, SSRIs have low lethal potential.

However, in the past decade there has been much controversy over whether the SSRI antidepressants can induce suicidal ideation and/or behavior in a small minority of cases. A number of case reports appeared in 1990-1991 describing patients who had developed suicidal preoccupations after starting treatment with fluoxetine (e.g., King et al., 1991 [children]; Masand and Dewan, 1991; Masand et al., 1991; Teicher et al., 1990 [adults]). These reports were not supported by meta-analyses and reanalyses of large SSRI treatment trials of depressed, bulimic, or anxious patients (Beasley et al., 1991; Letizia et al., 1996; Montgomery et al., 1995). The conclusion was reached that suicidal ideation is a common feature of depression and that its prevalence in SSRI-treated depressed patients is no greater than expected.

However, one reanalysis (Mann and Kapur, 1991) of data presented in certain of these studies suggested that new ideation was significantly more common in SSRI-treated depressed patients who had not previously reported suicidal ideation. Furthermore, in a naturalistic challenge study, Rothschild and Locke (1991) were able to reinduce suicidal ideas in a small series of patients who had first experienced ideation after starting treatment with fluoxetine. These patients had also experienced akathisia as a complication of fluoxetine treatment, and a relationship between suicidality and fluoxetine-induced akathisia has been noted by others (Hamilton and Opler, 1992).

At this stage, the wisest course of action for the practitioner is to be particularly observant during the early stages of fluoxetine treatment of a depressed adolescent, to inquire systematically about suicidal ideation before and after treatment is started, and to be especially alert to the possibility of suicidality if SSRI treatment is associated with the onset of akathisia.

Clinicians should be cautious about prescribing medications that may reduce self-control, such as the benzodiazepines and phenobarbital. Phenobarbital also has a high lethal potential if taken in overdose (Carlsten et al., 1996). Montgomery (1997) noted that benzodiazepines may disinhibit some individuals who then exhibit aggression and suicide attempts, and there are suggestions of similar effects from the antidepressants, maprotiline and amitriptyline, the amphetamines, and phenobarbital (Carlsten et al., 1996). Amphetamines or other stimulant medication should be prescribed only when treating suicidal children and adolescents with ADHD. Stimulants are the first line of treatment for children with ADHD. Tricyclics should not be prescribed, because of their greater lethal potential. 
In summary, lithium or a mood stabilizer can be labeled as the first line of pharmacological treatment for children and adolescents with bipolar disorder and should be prescribed before an antidepressant. SSRIs are the preferred psychopharmacological treatment for childhood and adolescent depression, with caution that suicidal youth on SSRIs must be watched for any increase in agitation or suicidality. Stimulant medications should be prescribed only for children and adolescents with ADHD. While medications may be essential in stabilizing and treating the suicidal child and adolescent, all administration must be carefully monitored by a third party who can report any unexpected change of mood, increase in agitation or emergency state, or unwanted side effects, and who can regulate dosage.

\section{PREVENTION}

\section{COMMUNITY-BASED SUICIDE PREVENTION}

The principal public health approaches to suicide prevention have been (1) crisis hotlines; (2) method control; (3) indirect case-finding by educating potential gatekeepers, teachers, parents, clergy, and peers to identify the "warning signs" of an impending suicide; (4) direct case-finding among high school or college students or among the patients of primary practitioners by screening for conditions that place teenagers at risk for suicide; (5) media counseling to minimize imitative suicide; and (6) training professionals to improve recognition and treatment of mood disorders.

\section{CRISIS HOTLINES}

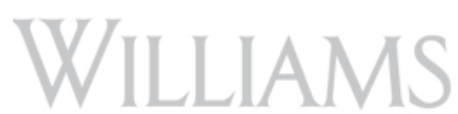

Although crisis hotlines are available almost everywhere in the United States, research so far has been fairly limited and has failed to show that crisis hotlines have an impact on the incidence of suicide. Possible reasons for this include the following:

1. Actively suicidal individuals (males and individuals with an acute mental disturbance) do not call hotlines, because they are acutely disturbed, preoccupied, or intent on not being deflected from their intended course of action.

2. Suicidal individuals may fail to reach the hotline. Hotlines are often busy, and there may be a long wait before a call is answered, so callers disconnect.

3. The advice given through a hotline may be stereotyped, inappropriate for the caller's needs, or perceived as unhelpful by the caller.

4. Gender preferences in seeking help result in the large majority of callers being females, whereas males are at the greatest risk for suicide.

While each of these deficiencies is potentially modifiable, to date there have been no systematic attempts to do so. Research studies in this area have been sparse and are sorely needed.

\section{METHOD RESTRICTION}

Method preference varies by gender and by nationality. In the United States the most common method for committing suicide is by firearm, and it has been suggested that reducing firearm availability will reduce the incidence of suicide (Moscicki, 1995). However, a natural experiment in Great Britain makes this unlikely. The favored suicide method, self-asphyxiation with coal gas, became impossible after the introduction of natural gas. This resulted in a marked, but not permanent, decline in the suicide rate. Within a decade, the suicide rate had returned to previous levels, and suicides were being committed by alternate means. There is, as yet, no good evidence that reducing access to firearms by gun security laws has a significant impact on suicides attributable to firearms, although they do have an impact on accidental deaths from firearms (Cummings et al., 1997). Raising the minimum legal drinking age for young adults does appear to reduce the suicide rate in the affected age group (Birckmayer and Hemenway, 1999).

\section{INDIRECT CASE-FINDING THROUGH EDUCATION}

Controlled studies (Shaffer et al., 1991; Spirito et al., 1988a; Vieland et al., 1991) have failed to show that classes for high school students about suicide increase students' help-seeking behavior when they are troubled or depressed. On the other hand, there is evidence that previously suicidal adolescents are perturbed by exposure to such classes (Shaffer et al., 1990). Such educational programs seem, therefore, to be both an ineffective mode of case-finding and to carry with them an unjustified risk of activating suicidal thoughts.

\section{DIRECT CASE-FINDING}

Direct case-finding is an excellent and cost-effective way to identify possibly at-risk children and adolescents in a school setting (Reynolds, 1991; Shaffer et al., 1996b). It may also be used in detention centers or foster care facilities. The direct screening may target all children and has been used in various high schools across the country (Reynolds, 1991; Shaffer et al., 1996b); it is highly sensitive.

There is evidence that adolescents will-if asked in a nonthreatening way-provide accurate information about their own suicidal thoughts or behaviors. A sensible approach to suicide prevention, therefore, is to systematically screen 15 - to 19year-olds (the age group at greatest risk for such attempts) for (1) previous suicide attempts; (2) recent, serious, suicidal preoccupations; (3) depression; or (4) complications of substance or alcohol use. Clearly, screening programs need to go beyond identifying a teenager with a high-risk profile. Youth identified in this way should be referred for evaluation and, if necessary, treatment. Contingency arrangements may need to be made to assist uninsured adolescents with help if it is needed. 


\section{MEDIA COUNSELING}

The Centers for Disease Control and Prevention (from a 1994 workshop) and the American Foundation for Suicide Prevention (1999) have issued sensible guidelines for reporters and editors, pointing to the risks of exaggerated or prominent coverage of youth suicide in general and of the risks in focusing attention on an individual suicide. These sensible guidelines, excerpted in Appendix 2, should be known to child and adolescent clinicians who are engaged in public health practice, even though there is as yet no good evidence that their application is effective in reducing the suicide rate.

\section{TRAINING}

After a 2-day course of training on how to evaluate mood disorders and suicidality, preliminary and as-yet-unreplicated studies in Sweden (Rihmer et al., 1995) suggest that educating primary practitioners to better identify and treat mood disorders results in a reduction in the number of suicides and suicide attempts (among females) and an increase of antidepressant prescriptions and hospitalizations. Because the optimal treatment of adolescent depression is not as well understood as that of adult depression, this is an option that may prove to be useful but that, at the moment, is still preliminary. Educating all clinicians who encounter adolescents, not just mental health clinicians, in how to recognize and, if necessary, refer the suicidal child or adolescent is a worthwhile end in itself, regardless of its impact on suicide.

\section{POSTVENTION}

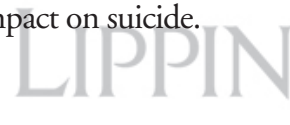

When a parent or sibling commits suicide, the bereaved prepubertal child is at risk for symptoms of anxiety and depression. A sizable proportion of these children do in fact develop anxiety disorders involving posttraumatic stress disorder (PTSD) and mood disorders involving major depression (Pfeffer et al., 1997). Having a friend or acquaintance commit suicide increases the likelihood of major depression, anxiety disorder, suicidal ideation, and PTSD onset in adolescents in the 6 months immediately following the suicide (Brent et al., 1996b; Pfeffer, 1997). Prior psychiatric disorder and a family history of psychiatric disorder, particularly affective illness or previous exposure to suicidal behavior, increase vulnerability for adolescents exposed to a peer's suicide (Brent et al., 1996b). Parental psychiatric symptoms such as depression, PTSD, or other anxiety states are directly related to the severity of bereaved children's propensity for symptoms of anxiety or depression (Pfeffer, 1997). Actually witnessing the suicide or viewing the scene afterward increases the risk of adolescent PTSD and anxiety disorder (Brent et al., 1996b). While intervention is exceedingly important in this immediate period, long-term support and services are also necessary. Three years after an adolescent suicide, adolescent friends who spoke to the victim the day before the suicide and felt they had knowledge of the impending suicide and failed to prevent it are most likely to continue to suffer from major depression and PTSD (Brent et al., 1996b). Clinicians need to work carefully with adolescents who are harboring guilt and must recognize that the effects of an adolescent suicide are far-reaching. Bereavement should be distinguished from depression and psychiatric disorder. As an adolescent suicide attempt also may increase risk of suicidal behavior and psychiatric disorder in friends and acquaintances (Hazell and Lewin, 1993), clinicians need to work with adolescents whose friend or acquaintance has attempted suicide as well.

The goal of the clinician is to decrease the likelihood of others identifying with the suicidal behavior of the deceased as a coping strategy in dealing with adversity (Brent, 1997). Psychoeducational counseling may reduce the risk for suicidal behavior in these circumstances. Intervention is also needed to promote grief and mourning and to decrease the child's or teenager's personal sense of guilt, trauma, and social isolation (Pfeffer, 1997). This treatment can be given in individual meetings, at group sessions with other teenagers, or in conjunction with parents who need help to support the adaptive capacities of their children and adolescents. School professionals sometimes offer programs of this kind and can be invaluable in identifying grieving friends who may need help.

\section{CONFLICT OF INTEREST}

As a matter of policy, some of the authors of AACAP practice parameters are in active clinical practice and may have received income related to treatments discussed in these parameters. Some authors may be involved primarily in research or other academic endeavors and also may have received income related to treatments discussed in these parameters. To minimize the potential for these parameters to contain biased recommendations due to conflict of interest, the parameters were reviewed extensively by Work Group members, consultants, and Academy members; authors and reviewers were asked to base their recommendations on an objective evaluation of the available evidence. Authors and reviewers who believed that they might have a conflict of interest that would bias, or appear to bias, their work on these parameters were asked to notify the Academy.

\section{SCIENTIFIC DATA AND CLINICAL CONSENSUS}

Practice parameters are strategies for patient management, developed to assist clinicians in psychiatric decision-making. These parameters, based on evaluation of the scientific literature and relevant clinical consensus, describe generally accepted approaches to assess and treat specific disorders or to perform specific medical procedures. The validity of scientific findings was judged by design, sample selection and size, inclusion of comparison groups, generalizability, and agreement with other studies. Clinical consensus was determined through extensive 
review by the members of the Work Group on Quality Issues, child and adolescent psychiatry consultants with expertise in the content area, the entire Academy membership, and the Academy Assembly and Council.

These parameters are not intended to define the standard of care, nor should they be deemed inclusive of all proper methods of care or exclusive of other methods of care directed at obtaining the desired results. The ultimate judgment regarding the care of a particular patient must be made by the clinician in light of all the circumstances presented by the patient and his or her family, the diagnostic and treatment options available, and available resources. Given inevitable changes in scientific information and technology, these parameters will be reviewed periodically and updated when appropriate.

\section{APPENDIX 1: SELECTED WEB SITES WITH SUICIDE FACTS AND RESOURCES}

The following is a list of Web sites that may be relevant to the clinician seeking more information or to the family and friends of a suicidal youth. These Web sites were obtained by an Internet search on the keywords "suicide" and "suicide prevention" through various search engines on May 1, 1999. The list below is by no means comprehensive. Sites were selected that represent well-known organizations dealing with suicide and mental illness in the United States and other Englishspeaking countries.

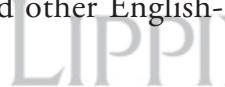

American Academy of Child and Adolescent Psychiatry

- http://www.aacap.org/

Facts for Families

- Teen Suicide: http://www.aacap.org/publications/factsfam/ suicide.htm

- The Depressed Child: http://www.aacap.org/publications/ factsfam/depressd.htm

- Manic-Depressive Disorder in Teens: http://www.aacap. org/publications/factsfam/bipolar.htm

- Gay and Lesbian Teens: http://www.aacap.org/publications/ factsfam/63.htm

American Association of Suicidology

- http://www.suicidology.org/

\section{American Foundation for Suicide Prevention}

- http://www.afsp.org/ (Excellent site with links to research articles and youth suicide facts; has information for those interested in pursuing research.)

\section{American Psychiatric Association}

- Teen Suicide: http://www.psych.org/ (Good summary for parents and peers listing where to get help.)
Australian National Youth Suicide Prevention Strategy

Communications Project

- http://www.aifs.org.aulexternal/ysp/ysplinks.html (Guide to many excellent Australian Web sites listing prevention strategies and resources.)

\section{Canadian Association for Suicide Prevention}

- Community Lifelines: http://www3.sympatico.calmasecard/ (Nonprofit national Canadian association; text in French and English.)

\section{Centers for Disease Control and Prevention}

CDC Prevention Guidelines

- Programs for the Prevention of Suicide Among Adolescents and Young Adults (1994): http://aepo-xdv-www.epo.cdc.gov/ wonder/prevguid/m0031525/m0031525.htm

- Suicide Contagion and the Reporting of Suicide: Recommendations From a National Workshop (1994): http://aepo- $x d v$ -

www.epo.cdc.gov/wonder/prevguid/m0031539/m0031539.htm

- Youth Suicide Prevention Programs: A Resource Guide (1992): http://aepo-xdv-www.epo.cdc.gov/wonder/prevguid/ p0000024/p0000024.htm

- CDC Recommendations for a Community Plan for the Prevention and Containment of Suicide Clusters (1988): http://aepo-xdv-www.epo.cdc.gov/wonder/prevguid/p0000214/p0000214.htm

- National Center for Injury Prevention and Control: Suicide and Violence (fact sheet): $h t t p: / / w w w . c d c$.gov/ncipcldvp/suifacts. htm

\section{National Depressive and Manic-Depressive Association}

- http://www.ndmda.org/ Suicide: http://www.ndmda.org/suicide.htm

- Suicide and Depressive Illness Booklet: http://www.ndmda. org/suicide.htm

(Many excellent links on suicide and child and adolescent depression and manic depression for family and patients.)

National Institute of Mental Health

- Suicide Research Consortium: http://www.nimh.nih.gov/ research/suicide.htm (Has suicide fact sheet, epidemiological information, bibliographies, and information for those interested in pursuing research.)

\section{Prevention Yellow Pages}

- Suicide: http://www.tyc.state.tx.us/prevention/40001ref.html \#SUI (Reference list for many recent research articles on programs designed to prevent youth suicide.) 


\section{Suicide Information and Education Centre}

- http://www.siec.cal (Extensive resources provided, as well as answers to frequently asked questions and library resources.)

Site for Survivors

- 1000 Deaths (by Christine Smith): http://www.1000deaths. $\mathrm{com} /$

E-mail Support for Survivors

- suicide-survivors-request@research.canon.com.au

\section{APPENDIX 2: MEDIA GUIDELINES FOR CLINICIANS AND REPORTERS}

\section{GENERAL CONCERNS AND RECOMMENDATIONS}

Source: Centers for Disease Control and Prevention, Prevention Guidelines Database (1994), Suicide Contagion and the Reporting of Suicide: Recommendations From a National Workshop MMWR 43(RR-6):9-18 (http://aepo-xdv www.epo.cdc.gov/ wonder/prevguid/m0031539/m0031539.htm).

The following concerns and recommendations should be reviewed and understood by health professionals, suicidologists, public officials, and others who provide information for the reporting of suicide:

- Suicide is often newsworthy, and it will probably be reported. The mission of a news organization is to report to the public information on events in the community. If a suicide is considered newsworthy, it will probably be reported. Health care providers should realize that efforts to prevent news coverage may not be effective, and their goal should be to assist news professionals in their efforts toward responsible and accurate reporting.

- "No comment" is not a productive response to media representatives who are covering a suicide story. Refusing to speak with the media does not prevent coverage of a suicide; rather, it precludes an opportunity to influence what will be contained in the report. Nevertheless, public officials should not feel obligated to provide an immediate answer to difficult questions. They should, however, be prepared to provide a reasonable timetable for giving such answers or be able to direct the media to someone who can provide the answers.

- All parties should understand that a scientific basis exists for concern that news coverage of suicide may contribute to the causation of suicide. Efforts by persons trying to minimize suicide contagion are easily misinterpreted. Health officials must take the time to explain the carefully established, scientific basis for their concern about suicide contagion and how the potential for contagion can be reduced by responsible reporting.

- Some characteristics of news coverage of suicide may contribute to contagion, and other characteristics may help prevent suicide. Clinicians and researchers acknowledge that it is not news coverage of suicide per se, but certain types of news coverage, that promote contagion. Persons concerned with preventing suicide contagion should be aware that certain characteristics of news coverage, rather than news coverage itself, should be avoided.

- Health professionals or other public officials should not try to tell reporters what to report or how to write the news regarding suicide. If the nature and apparent mechanisms of suicide contagion are understood, the news media are more likely to present the news in a manner that minimizes the likelihood of such contagion. Instead of dictating what should be reported, public officials should explain the potential for suicide contagion associated with certain types of reports and should suggest ways to minimize the risk for contagion.

- Public officials and the news media should carefully consider what is to be said and reported regarding suicide. Reporters generally present the information that they are given. Impromptu comments about a suicide by a public official can result in harmful news coverage. Given the potential risks, public officials and the media should seek to minimize these risks by carefully considering what is to be said and reported regarding suicide.

ASPECTS OF NEWS COVERAGE THAT CAN PROMOTE SUICIDE CONTAGION

Source: American Foundation for the Prevention of Suicide, Gould MS, Kramer R. Reporting a suicide. American Foundation for the Prevention of Suicide, 120 Wall Street, 22nd Floor, New York, NY 10025; (212) 363-3500; www.afsp.org.

The American Foundation for Suicide Prevention has issued the following good suggestions, developed by Madelyn Gould, Ph.D., and Rachel Kramer, Sc.D., for how journalists might be able to minimize the risk of inducing suicidal behavior.

- It is misleading to present suicide as the inexplicable act of an otherwise "healthy" person. Acknowledge the multidetermined nature of suicide, particularly the underlying psychiatric problems that may not be immediately apparent to an outside observer.

- Communicate that suicide is preventable by providing models of effective treatment. Provide resources for further information and help.

- Question whether the suicide is unusual or newsworthy. People may not need to be informed about all suicides.

- Be mindful that pictures of the victim and/or grieving relatives and friends may foster a pathological identification with the victim and inadvertently glorify the death.

- Avoid excessive and prominent coverage.

- Try to oversee headlines. Inappropriate headlines can detract from an otherwise helpful story.

- Limit detailed description of method, to avoid modeling behavior. 


\section{REFERENCES}

References marked with an asterisk are particularly recommended.

Adams M, Adams J (1991), Life events, depression, and perceived problemsolving alternatives in adolescents. J Child Psychol Psychiatry 32:811-820

Alcohol, Drug Abuse, and Mental Health Administration (1989), Report of the Secretary's Task Force on Youth Suicide, Vol 1: Overview and Recommendations (DHHS Publication ADM 89-1621). Washington, DC: US Government Printing Office

American Academy of Child and Adolescent Psychiatry (1998), Practice parameters for the assessment and treatment of children and adolescents with depressive disorders. J Am Acad Child Adolesc Psychiatry 37(suppl): 63S-83S

American Foundation for Suicide Prevention (1999), Today's Suicide Attempter Could Be Tomorrow's Suicide (poster). New York: American Foundation for Suicide Prevention, 1-888-333-AFSP

Amsel L, Mann JJ (2001), Biological aspects of suicidal behavior. In: New Oxford Textbook of Psychiatry, Gelder MG, Lopez-Ibor JJ, Andreasen NC, eds. Oxford, England: Oxford University Press, Vol I, pp 1045-1050

Andrews JA, Lewinsohn PM (1992), Suicidal attempts among older adolescents: prevalence and co-occurrence with psychiatric disorders. J Am Acad Child Adolesc Psychiatry 31:655-662

Arango V, Underwood MD, Mann JJ (1997), Biologic alterations in the brainstem of suicides. Psychiatr Clin North Am 20:581-593

Beasley CM Jr, Dornseif BE, Bosomworth JC et al. (1991), Fluoxetine and suicide: a meta-analysis of controlled trials of treatment for depression. BMJ 303:685-692

Beck AT, Kovacs M, Weissman A (1979a), Assessment of suicide intention: the Scale for Suicide Ideation. J Consult Clin Psychol 47:343-352

Beck AT, Rush AJ, Shaw BF, Emery G (1979b), Cognitive Therapy of Depression. New York: Guilford

Beck AT, Schuyler D, Herman I (1974a), Development of suicidal intent scales. In: The Prediction of Suicide, Beck AT, Resnik HLP, Lettieri DJ, eds. Bowie, MD: Charles Press, pp 45-56

Beck AT, Weissman A, Lester D, Trexler L (1974b), The measurement of pessimism: the Hopelessness Scale. J Consult Clin Psychol 42:861-865

Berman AL, Jobes DA (1991), Adolescent Suicide: Assessment and Intervention Washington, DC: American Psychological Association

Birckmayer J, Hemenway D (1999), Minimum-age drinking laws and youth suicide, 1970-1990. Am J Public Health 89:1365-1368

*Birmaher B, Brent DA, Kolko D et al. (2000), Clinical outcome after shortterm psychotherapy for adolescents with major depressive disorder. Arch Gen Psychiatry 57:29-36

Bollen KA, Philips DP (1982), Imitative studies: a national study of the effects of television news stories. Am Sociol Rev 47:802-809

Boyd JH, Moscicki EK (1986), Firearms and youth suicide. Am J Public Health 76:1240-1242

Brent DA (1997), The aftercare of adolescents with deliberate self-harm. $J$ Child Psychol Psychiatry 38:277-286

*Brent DA, Baugher M, Bridge J, Chen T, Chiappetta L (1999), Age- and sexrelated risk factors for adolescent suicide. J Am Acad Child Adoles Psychiatry 38:1497-1505

Brent DA, Bridge J, Johnson BA, Connolly J (1996a), Suicidal behavior runs in families: a controlled family study of adolescent suicide victims. Arch Gen Psychiatry 53:1145-1152

Brent DA, Holder D, Kolko D et al. (1997), A clinical psychotherapy trial for adolescent depression comparing cognitive, family, and supportive therapy. Arch Gen Psychiatry 54:877-885

Brent DA, Johnson B, Bartle S et al. (1993a), Personality disorder, tendency to impulsive violence, and suicidal behavior in adolescents. J Am Acad Child Adolesc Psychiatry 32:69-75

Brent DA, Johnson BA, Perper J et al. (1994a), Personality disorder, personality traits, impulsive violence, and completed suicide in adolescents. $J \mathrm{Am}$ Acad Child Adolesc Psychiatry 33:1080-1086

Brent DA, Kalas R, Edelbrock C, Costello AJ, Dulcan MK, Conover N (1986), Psychopathology and its relationship to suicidal ideation in childhood and adolescence. J Am Acad Child Psychiatry 25:666-673

*Brent DA, Moritz G, Bridge J, Perper J, Canobbio R (1996b), Long-term impact of exposure to suicide: a three-year controlled follow-up. J Am Acad Child Adolesc Psychiatry 35:646-653
Brent DA, Perper JA (1995), Research in adolescent suicide: implications for training, service delivery, and public policy. Suicide Life Threat Behav 25:222-230

Brent DA, Perper JA, Allman CJ (1987), Alcohol, firearms, and suicide among youth: temporal trends in Allegheny County, Pennsylvania, 1960 to 1983. JAMA 257:3369-3372

Brent DA, Perper JA, Allman CJ, Moritz GM, Wartella ME, Zelenak JP (1991), The presence and accessibility of firearms in the homes of adolescent suicides: a case-control study. JAMA 266:2989-2995

Brent DA, Perper JA, Goldstein CE et al. (1988), Risk factors for adolescent suicide: a comparison of adolescent suicide victims with suicidal inpatients. Arch Gen Psychiatry 45:581-588

Brent DA, Perper J, Moritz G, Baugher M, Allman C (1993b), Suicide in adolescents with no apparent psychopathology. J Am Acad Child Adolesc Psychiatry 35:494-500

Brent DA, Perper JA, Moritz G, Baugher M, Schweers J, Roth C (1993c), Firearms and adolescent suicide: a community case-control study. Am J Dis Child 147:1066-1071

Brent DA, Perper JA, Moritz G et al. (1994b), Family risk factors for adolescent suicide: a case-control study. Acta Psychiatr Scand 89:52-58

Brent DA, Poling K (1989, revised 1997), Cognitive Therapy Manual for Depressed and Suicidal Youth. Pittsburgh: Western Psychiatric Institute and Clinic, University of Pittsburgh Medical Center

Brent DA, Poling K, McKain B, Baugher M (1993d), A psychoeducational program for families of affectively ill children and adolescents. J Am Acad Child Adolesc Psychiatry 32:770-774

Brodsky BS, Malone KM, Ellis SP, Dulit RA, Mann JJ (1997), Characteristics of borderline personality disorder associated with suicidal behavior. $\mathrm{AmJ}$ Psychiatry 154:1715-1719

*Brown J, Cohen P, Johnson JG, Smailes EM (1999), Childhood abuse and neglect: specificity of effects on adolescent and young adult depression and suicidality. J Am Acad Child Adolesc Psychiatry 38:1490-1496

Brown M, King E, Barraclough B (1995), Nine suicide pacts: a clinical study of a consecutive series 1974-93. Br J Psychiatry 167:448-451

Carlson GA, Asarnow JR, Orbach I (1994), Developmental aspects of suicidal behavior in children and developmentally delayed adolescents. In:

Children, Youth, and Suicide: Developmental Perspectives (New Directions for Child Development Series, No. 64), Noam GG, Borst S et al., eds. San Francisco: Jossey-Bass, pp. 93-107

Carlsten A, Allebeck P, Brandt L (1996), Are suicide rates in Sweden associated with changes in the prescribing of medicines? Acta Psychiatr Scand 94:94-100

Centers for Disease Control and Prevention (1998), Youth risk behavior surveillance-United States, 1997. MMWR SS-3

Clarke GN, Rohde P, Lewinsohn PM, Hops H, Seeley JR (1999), Cognitivebehavioral treatment of adolescent depression: efficacy of acute group treatment and booster sessions. J Am Acad Child Adolesc Psychiatry $38: 272-279$

Corbitt EM, Malone KM, Haas GL, Mann JJ (1996), Suicidal behavior in patients with major depression and comorbid personality disorders. $J$ Affect Disord 39:61-72

Coté TR, Biggar RJ, Dannenberg AL (1992), Risk of suicide among persons with AIDS: a national assessment. JAMA 268:2066-2068

Cummings P, Grossman DC, Rivara FP, Koepsell TD (1997), State gun safe storage laws and child mortality due to firearms. JAMA 278:1084-1086

Dannenberg AL, McNeil JG, Brundage JF, Brookmeyer R (1996), Suicide and HIV infection: mortality follow-up of 4147 HIV-positive military service applicants. JAMA 276:1743-1746

de Wilde EJ, Kienhorst IC, Diekstra RF, Wolters WH (1992), The relationship between adolescent suicidal behavior and life events in childhood and adolescence. Am J Psychiatry 149:45-51

Deykin EY, Alpert JJ, McNamara JJ (1985), A pilot study of the effect of exposure to child abuse or neglect on adolescent suicidal behavior. Am J Psychiatry 142:1299-1303

Egan MP, Rivera SG, Robillard RR, Hanson A (1997), The "no suicide contract": helpful or harmful? J Psychosoc Nurs Ment Health Serv 35:31-33

Elkin I, Shea MT, Watkins JT et al. (1989), National Institute of Mental Health Treatment of Depression Collaborative Research Program: general effectiveness of treatments. Arch Gen Psychiatry 46:971-982; discussion 983 
Emslie G, Rush A, Weinberg W et al. (1997), A double-blind, randomized placebo-controlled trial of fluoxetine in children and adolescents with depression. Arch Gen Psychiatry 54:1031-1037

Faulkner AH, Cranston K (1998), Correlates of same-sex sexual behavior in random sample of Massachusetts high school students. Am J Public Health 88:262-266

Fergusson DM, Horwood LJ, Beautrais AL (1999), Is sexual orientation related to mental health problems and suicidality in young people? Arch Gen Psychiatry 56:876-880

Fergusson DM, Horwood LJ, Lynskey MT (1996), Childhood sexual abuse and psychiatric disorder in young adulthood, II: psychiatric outcomes of childhood sexual abuse. J Am Acad Child Adolesc Psychiatry 35:1365-1374

Fergusson DM, Lynskey MT (1995a), Antisocial behaviour, unintentiona and intentional injuries during adolescence. Criminal Behav Ment Health 5:312-329

Fergusson DM, Lynskey MT (1995b), Suicide attempts and suicidal ideation in a birth cohort of 16-year-old New Zealanders. J Am Acad Child Adolesc Psychiatry 34:1308-1317

Fisher P, Shaffer D, Gould MS, Parides M (1995), The New York Suicide Study: methods used and effect of immediate stressors. In: Scientific Proceedings of the XVIIIth Congress of the International Association for Suicide Prevention and Crisis Intervention, Venice, Italy

Garofalo R, Wolf RC, Kessel S, Palfrey SJ, DuRant RH (1998), The association between health risk behaviors and sexual orientation among a schoolbased sample of adolescents. Pediatrics 101:895-902

Garrison CZ, Lewinshon PM, Marsteller F, Langhinrichsen J, Lann I (1991), The assessment of suicidal behavior in adolescents. Suicide Life Threat Behav 21:217-230

Gibbs JT (1997), African-American suicide: a cultural paradox. Suicide Life Threat Behav 27:68-79

Goldston DB (2000), Assessment of Suicidal Behaviors and Risk Among Children and Adolescents. Technical report submitted to NIMH under contract 263-MD-909995; http://www.nimh.nih.gov/research/measures.pdf

Goldston DB, Reboussin DM, Kelley A, Ievers C, Brunstetter R (1996), First-time suicide attempters, repeat attempters, and previous attempters on an adolescent inpatient psychiatry unit. J Am Acad Child Adolesc Psychiatry 35:631-639

Gould MS (1990), Suicide clusters and media exposure. In: Suicide Over the Life Cycle, Blumenthal SJ, Kupfer DJ, eds. Washington, DC: American Psychiatric Press

Gould MS (2001a), Suicide and the media. In: Suicide Prevention: Clinical and Scientific Aspects, Hendin H, Mann JJ, eds. New York: Annals of the New York Academy of Sciences

Gould MS (2001b), Teenage Suicide Clusters. Child Psychiatry Grand Rounds, Columbia University, New York, June

Gould MS, Davidson L (1988), Suicide contagion among adolescents. In: Advances in Adolescent Mental Health, Volume III: Depression and Suicide, Stiffman AR, Feldman RA, eds. Greenwich, CT: JAI Press C L I

Gould MS, Fisher P, Parides M, Flory M, Shaffer D (1996), Psychosocial risk factors of child and adolescent completed suicide. Arch Gen Psychiatry 53:1155-1162

*Gould MS, King R, Greenwald S et al. (1998), Psychopathology associated with suicidal ideation and attempts among children and adolescents. J Am Acad Child Adolesc Psychiatry 37:915-923

Gould MS, Shaffer D (1986), The impact of television movies: evidence of imitation. N Engl J Med 315:690-694

Gould MS, Shaffer D, Kleinman M (1988), The impact of suicide in television movies: replication and commentary. Suicide Life Threat Behav 18:90-99

Gould MS, Wallenstein S, Kleinman M (1990a), Time-space clustering of teenage suicide. Am J Epidemiol 131:71-78 (abstracted in Psychiatry/ Neurology Digest, Northbrook, IL: Clinical Digest Series, 1990, and Psychiatry Digest, 1, 19, 1991; portions reprinted in college textbook titled Adolescence by Laurence Steinberg, New York: McGraw-Hill, 1996)

Gould MS, Wallenstein S, Kleinman M, O'Carroll P, Mercy J (1990b), Suicide clusters: an examination of age specific effects. Am J Public Health 80:211-212 (abstracted in Psychiatry/Neurology Digest, Northbrook, IL: Clinical Digest Series, 1990)

Greenhill L, Waslick B, Parides M, Fan B, Shaffer D, Mann J (1995), Biological studies in suicidal adolescent inpatients. In: Scientific Proceedings of the Annual Meeting of the American Academy of Child and Adolescent Psychiatry, New Orleans, p 124

Hafner H, Schmidtke A (1989), Do televised fictional suicide models produce suicides? In: Suicide Among Youth: Perspectives on Risk and Prevention, Pfeffer CR, ed. Washington, DC: American Psychiatric Press

Halperin JM, Sharma V, Siever LJ et al. (1994), Serotonergic function in aggressive and nonaggressive boys with attention deficit hyperactivity disorder. Am J Psychiatry 151:243-248

Hamilton MS, Opler LA (1992), Akathisia, suicidality, and fluoxetine. J Clin Psychiatry 53:401-406

Harrington R, Bredenkamp D, Groothues C, Rutter M, Fudge H, Pickles A (1994), Adult outcomes of childhood and adolescent depression, III: links with suicidal behaviours. J Child Psychol Psychiatr 35:1309-1319

Harrington R, Kerfoot M, Dyer E et al. (1998), Randomized trial of a homebased family intervention for children who have deliberately poisoned themselves. I Am Acad Child Adolesc Psychiatry 37:512-518

Hazell P, Lewin T (1993), Friends of adolescent suicide attempters and completers. J Am Acad Child Adolesc Psychiatry 32:76-81

Hewitt PL, Newton J, Flett GL, Callander L (1997), Perfectionism and suicide ideation in adolescent psychiatric patients. J Abnorm Child Psychol 25:95-101

Hollis C (1996), Depression, family environment, and adolescent suicidal behavior. I Am Acad Child Adolesc Psychiatry 35:622-630

Jacobsen LK, Rabinowitz I, Popper MS, Solomon RJ, Sokol MS, Pfeffer CR (1994), Interviewing prepubertal children about suicidal ideation and behavior. J Am Acad Child Adolesc Psychiatry 33:439-452

Johnstone J, Huws R (1997), Autoerotic asphyxia: a case report. J Sex Marital Ther 23:326-332

Juon HS, Ensminger ME (1997), Childhood, adolescent, and young adult predictors of suicidal behaviors: a prospective study of AfricanAmericans. J Child Psychol Psychiatry 38:553-563

Kaplan SJ, Pelcovitz D, Salzinger S, Mandel F, Weiner M (1997), Adolescent physical abuse and suicide attempts. J Am Acad Child Adolesc Psychiatry 36:799-808

Katz P (1995), The psychotherapeutic treatment of suicidal adolescents. Adolesc Psychiatry 20:325-341

Kazdin AE, Rodgers A, Golbus D (1986), The Hopelessness Scale for Children: psychometric characteristics and concurrent validity. J Consult Clin Psychol 54:241-245

Kellermann AL, Rivara FP, Somes G et al. (1992), Suicide in the home in relation to gun ownership. $N$ Engl J Med 327:467-472

Kernberg P (1994), Psychological interventions for the suicidal adolescent. Am J Psychother 48:52-63

Kienhorst ICWM, Wilde EJ, Diekstra RFW, Wolters WHG (1995), Adolescents' image of their suicide attempt. J Am Acad Child Adolesc Psychiatry 34:623-628

King CA, Franzese R, Gargan S, McGovern L, Ghaziuddin N, Naylor MW (1995), Suicide contagion among adolescents during acute psychiatric hospitalization. Psychiatr Serv 46:915-918

King CA, Hovey JD, Brand E, Wilson R (1997), Suicidal adolescents after hospitalization: parent and family impacts on treatment follow-through. I Am Acad Child Adolesc Psychiatry 36:85-93

King RA, Riddle MA, Chappell PB et al. (1991), Emergence of self-destructive phenomena in children and adolescents during fluoxetine treatment. $J$ Am Acad Child Adolesc Psychiatry 30:179-186

Kizer KW, Green M, Perkins CI, Doebbert G, Hughes MJ (1988), AIDS and suicide in California (letter). JAMA 260:1881

Klein DN, Lewinsohn PM, Seeley JR (1996), Hypomanic personality traits in a community sample of adolescents. J Affect Disord 38:135-143

Klerman GL, Weissman MM, Rounsaville BJ (1984), Interpersonal Psychotherapy of Depression. New York: Basic Books

Kovacs M, Goldston D, Gatsonis C (1993), Suicidal behaviors and childhoodonset depressive disorders: a longitudinal investigation. J Am Acad Child Adolesc Psychiatry 32:8-20

*Kruesi MJ, Grossman J, Pennington JM, Woodward PJ, Duda D, Hirsch JG (1999), Suicide and violence prevention: parent education in the emergency department. J Am Acad Child Adolesc Psychiatry 38:250-255

Kruesi MJ, Swedo SE, Hamburger SD, Potter WZ, Rapoport JL (1988), Concentration gradient of CSF monoamine metabolites in children and adolescents. Biol Psychiatry 24:507-514 
Kruesi MJP, Hibbs ED, Zahn TP et al. (1992), A two-year prospective followup study of children and adolescents with disruptive behavior disorders: prediction by cerebrospinal fluid 5-hydroxyindoleacetic acid, homovanillic acid, and autonomic measures. Arch Gen Psychiatry 49:429-435

Letizia C, Kapik B, Flanders WD (1996), Suicidal risk during controlled clinical investigations of fluvoxamine. J Clin Psychiatry 57:415-421

Linehan MM (1985), The Reasons for Living Inventory. In: Innovations in Clinical Practice: A Source Book, Keller PA, Ritt LG, eds. Sarasota, FL: Professional Resource Exchange, pp 321-330

Linehan MM (1993a), Cognitive Behavior Therapy of Borderline Personality Disorder. New York: Guilford

Linehan MM (1993b), Skills Training Manual for Treating Borderline Personality Disorder. New York: Guilford

Lock J, Steiner H (1999), Gay, lesbian, and bisexual youth risks for emotional, physical, and social problems: results from a community-based survey. $J$ Am Acad Child Adolesc Psychiatry 38:297-304

Loftin C, McDowall D, Wiersema B, Cottey TJ (1991), Effects of restrictive licensing of handguns on homicide and suicide in the District of Columbia. N Engl J Med 325:1615-1620

Lucas CP, Shaffer D, Parides M, Wilcox H (1995), Unstable reporting of suicidal behavior and ideation. Paper presented at XVIIth Congress of the International Association for Suicide Prevention and Crisis Intervention, Venice, Italy

Mann JJ (1998), The neurobiology of suicide. Nat Med 4:25-30

Mann JJ, Kapur S (1991), The emergence of suicidal ideation and behavior during antidepressant pharmacotherapy. Arch Gen Psychiatry 48:1027-1033

*Mann JJ, Stoff DM (1997), A synthesis of current findings regarding neurobiological correlates and treatment of suicidal behavior. Ann NY Acad Sci $836: 352-363$

Martin W (1984), Religiosity and United States suicide rates, 1972-1978. J Clin Psychol 40:1166-1169

Marttunen MJ, Hillevi MA, Henriksson MM, Lonnqvist JK (1991), Mental disorders in adolescent suicide: DSM-III-R Axes I and II diagnoses in suicides among 13- to 19-year-olds in Finland. Arch Gen Psychiatry 48:834-839

Marzuk PM, Tardiff K, Leon AC et al. (1997), HIV seroprevalence among suicide victims in New York City, 1991-1993. Am J Psychiatry 154:1720-1725

Masand P, Dewan M (1991), Association of fluoxetine with suicidal ideation. Am I Psychiatry 148:1603-1604

Masand P, Gupta S, Dewan M (1991), Suicidal ideation related to fluoxetine treatment (letter). N Engl J Med 324:420

May PA (1987), Suicide and self-destruction among American Indian youths. Am Indian Alsk Native Ment Health Res 1:52-69

McLeavey BC, Daly JD, Ludgate JW, Murray CM (1994), Interpersonal problem-solving skills training in the treatment of self-poisoning patients. Suicide Life Threat Behav 24:382-394

McManus BL, Kruesi MJ, Dontes AE, Defazio CR, Piotrowski JT, Woodward PJ (1997), Child and adolescent suicide attempts: an opportunity for emergency departments to provide injury prevention education. Am J Emerg Med 15:357-360

Miller AL, Rathus JH, Linehan MM, Wetzler S, Leigh E (1997), Dialectical behavior therapy adapted for suicidal adolescents. J Pract Psychiatry Behav Health 3:78-86

Miller KE, King CA, Shain BN, Naylor MW (1992), Suicidal adolescents' perceptions of their family environment. Suicide Life Threat Behav 22:226-239

Miller MC, Jacobs DJ, Gutheil TG (1998), Talisman or taboo: the controversy of the suicide-prevention contract. Harv Rev Psychiatry 6:78-87

Molnar BE, Shade SB, Kral AH, Booth RE, Watters JK (1998), Suicidal behavior and sexual/physical abuse among street youth. Child Abuse Negl 22:213-222

Montgomery SA (1997), Suicide and antidepressants. Ann NY Acad Sci 836:329-338

Montgomery SA, Dunner DL, Dunbar GC (1995), Reduction of suicidal thoughts with paroxetine in comparison with reference antidepressants and placebo. Eur Neuropsychopharmacol 5:5-13

*Montgomery SA, Montgomery D (1982), Pharmacological prevention of suicidal behaviour. J Affect Disord 4:291-298

Moscicki EK (1995), Epidemiology of suicide. Int Psychogeriatr 7:137-148

Mufson L, Moreau D, Weissman MM, Klerman GL (1993), Interpersonal Psychotherapy for Depressed Adolescents. New York: Guilford
*Mufson L, Weissman MM, Moreau D, Garfinkel R (1999), Efficacy of interpersonal psychotherapy for depressed adolescents. Arch Gen Psychiatry 56:573-579

Murphy GE (1998), Why women are less likely than men to commit suicide. Compr Psychiatry 39:165-175

National Center for Health Statistics (Centers for Disease Control and Prevention) (1999), Data provided by Division of Vital Statistics, Mortality Statistics Branch. Bethesda, MD: National Center for Health Statistics

National Center for Health Statistics (Centers for Disease Control and Prevention) (2000), Death rates for 72 selected causes, by 5-year age groups, race, and sex: United States, 1979-1997. Worktable GMWK 291 Trend B, plate 1 of 2, pages 485-490. Web site: http://www.cdc.gov/nchs/datawh/ statab/unpubd/mortabs.htm (detailed statistical tables on mortality from NCHS's data warehouse)

Neeleman J (1998), Regional suicide rates in the Netherlands: does religion still play a role? Int J Epidemiol 27:466-472

Neeleman J, Wessely S, Lewis G (1998), Suicide acceptability in African- and white Americans: the role of religion. J Nerv Ment Dis 186:12-16

Nordstrom P, Samuelsson M, Asberg M et al. (1994), CSF 5-HIAA predicts suicide risk after attempted suicide. Suicide Life Threat Behav 24:1-9

Ohring R, Apter A, Ratzoni G, Weizman R, Tyano S, Plutchik R (1996), State and trait anxiety in adolescent suicide attempters. J Am Acad Child Adolesc Psychiatry 35:154-157

*Olfson M, Marcus SC, Pincus HA, Zito JM, Thompson JW, Zarin DA (1998), Antidepressant prescribing practices of outpatient psychiatrists. Arch Gen Psychiatry 55:310-316

Osman A, Downs WR, Kopper BA et al. (1998), The Reasons for Living Inventory for Adolescents (RFL-A): development and psychometric properties. J Clin Psychol 54:1063-1078

*Pfeffer CR (1986), The Suicidal Child. New York: Guilford

Pfeffer CR (1990), Clinical perspectives on treatment of suicidal behavior among children and adolescents. Psychiatr Ann 20:143-150

*Pfeffer CR (1997), Childhood suicidal behavior: a developmental perspective. Psychiatr Clin North Am 20:551-562

Pfeffer CR, Conte HR, Plutchik R, Jerret I (1979), Suicidal behavior in latencyage children: an empirical study. J Am Acad Child Psychiatry 18:679-692

Pfeffer CR, Jiang H, Kakuma T (2000), Child-Adolescent Suicidal Potential Index (CASPI): a screen for risk for early onset suicidal behavior. Psychol Assess 12:304-318

*Pfeffer CR, Klerman GL, Hurt SW, Kakuma T, Peskin JR, Siefker CA (1993), Suicidal children grow up: rates and psychosocial risk factors for suicide attempts during follow-up. I Am Acad Child Adolesc Psychiatry 32:106-113

Pfeffer CR, Klerman GL, Hurt SW, Lesser M, Peskin JR, Siefker CA (1991), Suicidal children grow up: demographic and clinical risk factors for adolescent suicide attempts. J Am Acad Child Adolesc Psychiatry 30:609-616

*Pfeffer CR, Martins P, Mann J et al. (1997), Child survivors of suicide: psychosocial characteristics. J Am Acad Child Adolesc Psychiatry 36:65-74

Pfeffer CR, McBride PA, Anderson GM, Kakuma T, Fensterheim L, Khait V (1998), Peripheral serotonin measures in prepubertal psychiatric inpatients and normal children: associations with suicidal behavior and its risk factors. Biol Psychiatry 44:568-577

Pfeffer CR, Normandin L, Kakuma T (1994), Suicidal children grow up: suicidal behavior and psychiatric disorders among relatives. J Am Acad Child Adolesc Psychiatry 33:1087-1097

Pfeffer CR, Trad PV (1988), Suicidality and sadness in pre-school children. $J$ Dev Behav Pediatr 9:86-88

Piacentini J, Rotheram-Borus MJ, Gillis JR et al. (1995), Demographic predictors of treatment attendance among adolescent suicide attempters. J Consult Clin Psychol 63:469-473

Pine DS, Trautman PD, Shaffer D et al. (1995), Seasonal rhythm of platelet $\left[{ }^{3} \mathrm{H}\right]$ imipramine binding in adolescents who attempted suicide. Am J Psychiatry 152:923-925

Rao U, Weissman MM, Martin JA, Hammond RW (1993), Childhood depression and risk of suicide: a preliminary report of a longitudinal study. J Am Acad Child Adolesc Psychiatry 32:21-27

Reid WH (1998), Promises, promises: don't rely on patients' no-suicide/noviolence "contracts." J Pract Psychiatry Behav Health 4:316-318

Remafedi G, French S, Story M, Resnick MD, Blum R (1998), The relationship between suicide risk and sexual orientation: results of a populationbased study. Am J Public Health 88:57-60 
Reynolds WM (1987), Suicidal Ideation Questionnaire (SIQ). Odessa, FL: Psychological Assessment Resources, PO Box 998, Odessa, FL 33556

Reynolds WM (1991), A school-based procedure for the identification of adolescents at risk for suicidal behaviors. Fam Community Health 14:64-75

Rihmer Z, Rutz W, Pihlgran H (1995), Depression and suicide on Gotland: an intensive study of all suicides before and after a depression-training programme for general practitioners. J Affect Disord 35:147-152

Robins ER, Murphy GE, Wilkinson RH, Gassner S, Kayes J (1959), Some clinical considerations in the prevention of suicide based on a study of 134 successful suicides. Am J Public Health 49:888-899

Rosenthal PA, Rosenthal S (1984), Suicidal behavior by preschool children. Am J Psychiatry 141:520-525

Rotheram MJ (1987), Evaluation of imminent danger for suicide among youth. Am J Orthopsychiatry 57:102-110

Rotheram-Borus MJ, Piacentini J, Miller S, Graae F, Castro-Blanco D (1994), Brief cognitive-behavioral treatment for adolescent suicide attempters and their families. J Am Acad Child Adolesc Psychiatry 33:508-517

Rotheram-Borus MJ, Piacentini J, Miller S, Graae F, Castro-Blanco D (1996a), Toward improving treatment adherence among adolescent suicide attempters. Clin Child Psychol Psychiatry 1:99-108

*Rotheram-Borus MJ, Piacentini J, Van Rossem R et al. (1996b), Enhancing treatment adherence with a specialized emergency room program for adolescent suicide attempters. J Am Acad Child Adolesc Psychiatry 35:654-663

Rotheram-Borus MJ, Walker JU, Ferns W (1996c), Suicidal behavior among middle-class adolescents who seek crisis services. J Clin Psychol 52:137-143

Rothschild AJ, Locke CA (1991), Re-exposure to fluoxetine after serious suicide attempts by three patients: the role of akathisia. J Clin Psychiatry 52:491-493

Ryan ND, Varma D (1998), Child and adolescent mood disorders: experience with serotonin-based therapies. Biol Psychiatry 44:336-340

Sabbath JC (1969), The suicidal adolescent: the expendable child. J Am Acad Child Psychiatry 8:272-289

Safer DJ (1997), Adolescent/adult differences in suicidal behavior and outcome. Ann Clin Psychiatry 9:61-66

Sethi S, Seligman MEP (1993), Optimism and fundamentalism. Psychol Sci 4:256-259

Shaffer D, Craft L (1999), Methods of adolescent suicide prevention. J Clin Psychiatry 60(suppl 2):70-74

Shaffer D, Garland A, Vieland V, Underwood M, Busner C (1991), The impact of curriculum-based suicide prevention programs for teenagers. $J$ Am Acad Child Adolesc Psychiatry 30:588-596

Shaffer D, Gould M, Hicks RC (1994), Worsening suicide rate in black teenagers. Am J Psychiatry 151:1810-1812

* Shaffer D, Gould MS, Fisher P et al. (1996a), Psychiatric diagnosis in child and adolescent suicide. Arch Gen Psychiatry 53:339-348

Shaffer D, Vieland V, Garland A, Rojas M, Underwood M, Busner C (1990), Adolescent suicide attempters: response to suicide-prevention programs. JAMA 264:3151-3155
Shaffer D, Wilcox H, Lucas C, Hicks R, Busner C, Parides M (1996b), The development of a screening instrument for teens at risk for suicide. Poster presented at the 1996 meeting of the American Academy of Child and Adolescent Psychiatry, New York

Shea MT, Elkin I, Imber SD et al. (1992), Course of depressive symptoms over follow-up: findings from the National Institute of Mental Health Treatment of Depression Collaborative Research Program. Arch Gen Psychiatry 49:782-787

Sheehan W, Garfinkel BD (1988), Case study: adolescent autoerotic deaths. J Am Acad Child Adolesc Psychiatry 27:367-370

Silverman AB, Reinherz HZ, Giaconia RM (1996), The long-term sequelae of child and adolescent abuse: a longitudinal community study. Child Abuse Negl 20:709-723

Simon RI (1991), The suicide-prevention pact: clinical and legal considerations. In: American Psychiatric Press Review of Clinical Psychiatry and the Law II, Simon RI, ed. Washington, DC: American Psychiatric Press, pp 441-451

Spirito A (1997), Individual therapy techniques with adolescent suicide attempters. Crisis 18:62-64

Spirito A, Overholser J, Ashworth S, Morgan J, Benedict-Drew C (1988a), Evaluation of a suicide awareness curriculum for high-school students. J Am Acad Child Adolesc Psychiatry 27:705-711

Spirito A, Williams CA, Stark LJ, Hart KJ (1988b), The Hopelessness Scale for Children: psychometric properties with normal and emotionally disturbed adolescents. J Abnorm Psychol 16:445-458

Statham DJ, Heath AC, Madden PA et al. (1998), Suicidal behaviour: an epidemiological and genetic study. Psychol Med 28:839-855

Stein D, Apter A, Ratzoni G, Har-Even D, Avidan G (1998), Association between multiple suicide attempts and negative affects in adolescents. $J$ Am Acad Child Adolesc Psychiatry 37:488-494

Tatman SM, Greene AL, Karr LC (1993), Use of the Suicide Probability Scale (SPS) with adolescents. Suicide Life Threat Behav 23:188-203

Teicher MH, Glod C, Cole JO (1990), Emergence of intense suicidal preoccupation during fluoxetine treatment. Am J Psychiatry 147:207-210

Tondo L, Jamison KR, Baldessarini RJ (1997), Effect of lithium maintenance on suicidal behavior in major mood disorders. Ann N Y Acad Sci 836:339-351

Velting DM, Gould MS (1997), Suicide contagion. In: Review of Suicidology, Maris RW, Silverman MM, eds. New York: Guilford, pp 96-137

Vieland V, Whittle B, Garland A, Hicks R, Shaffer D (1991), The impact of curriculum-based suicide prevention programs for teenagers: an 18month follow-up. J Am Acad Child Adolesc Psychiatry 30:811-815

Wallace JD, Calhoun AD, Powell KE, O'Neil J, James SP (1996), Homicide and Suicide Among Native Americans, 1979-1992 (Violence Surveillance Series, No. 2). Atlanta: Centers for Disease Control and Prevention, National Center for Injury Prevention and Control

Weissman MM (1979), The psychological treatment of depression: evidence for the efficacy of psychotherapy alone, in comparison with, and in combination with pharmacotherapy. Arch Gen Psychiatry 36:1261-1269 